\title{
An Investigation of High-Temperature Precipitation in Powder-Metallurgy, Gamma/Gamma-Prime Nickel-Base Superalloys
}

\begin{abstract}
S.L. SEMIATIN, S-L. KIM, F. ZHANG, and J.S. TILEY
The high-temperature-precipitation behavior of a typical powder-metallurgy, gamma-gammaprime, nickel-base superalloy (LSHR) was determined and used to develop and validate a quantitative fast-acting model. To this end, a series of experiments comprising supersolvus solution treatment followed by continuous cooling at rates typical of those experienced during the manufacture of full-scale components was conducted for LSHR. The nucleation and growth of secondary-gamma-prime precipitates were deduced via metallography on samples water quenched at various temperatures during the cooling cycle. Further insight on nucleation and the extent of retained supersaturation during cooling was obtained from in situ synchrotron (X-ray diffraction) experiments involving cooling of LSHR samples at identical rates with or without a hold time at an intermediate temperature. The observations were interpreted using a fast-acting (spreadsheet) model which incorporated the important aspects of classical, homogeneous-nucleation theory and growth by bulk diffusion. In this regard, particular attention was paid to the determination of model input parameters such as the composition, free energy of formation, and surface energy of precipitates, and an effective diffusivity; the values so determined contrasted with those from existing thermodynamic and diffusion databases. It was demonstrated that fast-acting-model calculations based on a nickel-chromium pseudo-binary system gave good agreement with measurements of the evolution of precipitate volume fraction, number density, and size during continuous cooling.
\end{abstract}

DOI: $10.1007 / \mathrm{s} 11661-015-2748-0$

(C) The Minerals, Metals \& Materials Society and ASM International 2015

\section{INTRODUCTION}

COMMERCIAL nickel-base (gamma/gamma-prime) superalloys comprise a class of material for which the understanding and control of precipitation behavior is extremely important. The size and volume fraction of gamma-prime precipitates play a key role in controlling strength, fatigue, and other properties. ${ }^{[1-3]}$

Typically, the final heat treatment of components made from gamma/gamma-prime superalloys includes a solution treatment in the single-phase-gamma field or high in the two-phase, gamma-plus-gamma-prime field, followed by cooling at a rate which is determined by the cooling/quenching medium, the size of the part, and the location within in the part. The cooling rates that are imparted within the bulk (i.e., away from the free surface which is removed by machining) are usually of the order of 10 to $200 \mathrm{~K} / \mathrm{min}\left(10\right.$ to $\left.200{ }^{\circ} \mathrm{C} / \mathrm{min}\right)$. Following cool-down, an isothermal aging treatment at

S.L. SEMIATIN, Senior Scientist, Materials Processing/Processing Science, and J.S. TILEY, Senior Materials Engineer, are with the Air Force Research Laboratory, Materials and Manufacturing Directorate, AFRL/RXCM, Wright-Patterson Air Force Base, OH 45433. Contact e-mail: sheldon.semiatin@us.af.mil S-L. KIM, Research Scientist, is with UES, Inc., 4401 Dayton-Xenia Road, Dayton, $\mathrm{OH}$ 45432. F. ZHANG, President, is with CompuTherm LLC, Madison, WI 53719.

Manuscript submitted September 22, 2014.

Article published online 29 January 2015 a temperature approximately $50 \mathrm{~K}$ to $200 \mathrm{~K}\left(50{ }^{\circ} \mathrm{C}\right.$ to $200{ }^{\circ} \mathrm{C}$ ) above the service temperature is common.

For ingot-metallurgy alloys having relatively-low amounts of gamma prime in the fully-hardened state, the formation of precipitates can be avoided during cooling from the solution-treatment temperature. Precipitation hardening then relies on a final aging treatment. By contrast, more-highly-alloyed, powder-metallurgy (PM) superalloys often decompose during cooling. This precipitation usually occurs in several "bursts". At relatively small undercooling relative to the gamma prime solvus, secondary gamma prime (so-called to differentiate it from the coarse, primary gamma-prime dispersion developed during subsolvus extrusion or isothermal forging) nucleates over a relatively narrow temperature interval. During continued cooling, the secondary gamma prime grows via diffusion to a size typically in the range of 100 to $500 \mathrm{~nm}$. At temperatures several hundred kelvins below the solvus, diffusional growth becomes sluggish, matrix supersaturation increases again, and additional bursts of gamma-prime precipitates, referred to as tertiary (with a size of approximately 10 to $50 \mathrm{~nm})$ and quatary ( $~ 3$ to $10 \mathrm{~nm}$ in diameter) are formed.

Because of its importance with regard to the strengthening of metallic materials such as nickel-base superalloys, the modeling of precipitation reactions has received considerable attention in the literature. The phenomenon is frequently described in terms of nucleation, growth, and coarsening processes. ${ }^{[4,5]}$ 
For the case of homogeneous nucleation of spherical precipitates, the analysis is usually based on the determination of the critical radius of a stable cluster of precipitate atoms in terms of the balance between the reduction in volumetric (chemical) free energy $\left(\Delta \mathrm{G}^{*}\right)$ and the increase in matrix-precipitate surface energy $(\sigma)$ and elastic strain energy $\left(\Delta \mathrm{G}_{\mathrm{p}}\right) \cdot \cdot^{[4,6-12]}$ The rate of nucleation $(J)$ is then given by the product of (1) the concentration of embryos per unit volume (from statistical mechanics), (2) the rate of addition of atoms to embryos to make them into critical size, (3) a term (Zeldovich factor) which accounts for the loss of critical nuclei when atomic fluctuations drop selected particles below critical size, and (4) an exponential term ( incubation factor) quantifying transient phenomena prior to achievement of steady-state conditions. The simple theory reveals that $\mathbf{J}$ is a very strong function of both $\sigma$ and $\Delta \mathrm{G}^{*}$ due to the presence in the resulting equation of an exponential term whose argument includes $\sigma^{3}$ in the numerator and $\Delta \mathrm{G}^{* 2}$ in the denominator.

Precipitate growth is often found to be controlled by bulk diffusion through the matrix. A variety of solutions of the diffusion equation have been developed for this problem, each of which typically indicates that the rate of growth is a function of the instantaneous precipitate radius and the diffusivity and supersaturation of the diffusing solute(s). ${ }^{[4]}$ These solutions include the socalled constant radius solution (suitable for a vanishingly-small supersaturation) and the exact solution of Carslaw and Jaeger ${ }^{[13]}$ and Aaron, et al. ${ }^{[14]}$ Irrespective of the specific solution, the overlapping of the concentration gradients around neighboring precipitates ("soft impingement") must be taken into account for accurate predictions.

The increase in the average size of a dispersion of precipitates (i.e., coarsening) can be controlled by bulk diffusion or an interface reaction. In such cases, the work of Lifshitz, Slyosov, and Wagner ("LSW") $)^{[4,5,15,16]}$ often forms the basis of theoretical treatments. Strictly applicable for an infinitesimal volume fraction of precipitates in a two-component system, these analyses have been extended to treat multi-component systems with a finite volume fraction of precipitates which are not terminal solid solutions. ${ }^{[17-24]}$

The nucleation, growth, and coarsening of precipitates usually do not occur sequentially but often overlap. The degree of overlap depends on the instantaneous size of the precipitates and level of matrix supersaturation, among other factors. When supersaturations are high, nucleation and growth dominate reaction kinetics. At low supersaturations, growth and coarsening are typically rate limiting. Such interplay has been studied both experimentally ${ }^{[25-29]}$ and analytically. ${ }^{[30,31]}$

Various aspects of the nucleation, growth, and coarsening of model gamma-gamma-prime systems, usually with 2,3 , or 4 components heat treated under isothermal conditions, have been investigated. ${ }^{[25,26,28,29,32]}$ A modest amount of research for commercial gamma/gamma-prime PM superalloys has examined the phenomenology and modeling of precipitation during continuous cooling following solution treatment. ${ }^{[33-39]}$
Despite the substantial contributions of previous research in delineating the broad aspects of precipitation during cooling of multi-component commercial alloys, it is difficult to assess the quantitative validity of modeling approaches. This difficulty arises partly because of the limited amount of experimental data with which the models have been validated; in most cases, precipitate size and/or volume fractions only at the end of the cooling cycle have been determined. Secondly, the accuracy of model input parameters for the commercial alloys (e.g., $\Delta \mathrm{G}^{*}$ and diffusivity) has not been fully addressed. For example, the detailed work of Campbell et al. ${ }^{[40]}$ showed errors of approximately one order of magnitude when comparing the measured effective interdiffusion coefficients for $\mathrm{Al}, \mathrm{Cr}, \mathrm{Nb}, \mathrm{Ti}$, and $\mathrm{W}$ in the commercial PM superalloy Rene 88 with predictions from a mobility database. It is with these challenges in mind that the present work was undertaken. The specific objectives were threefold: (1) to develop an experimental database of observations of precipitation behavior during cooling (including size, volume fraction, and number density) for a typical PM superalloy, (2) develop and validate simple methods to determine the input material data for precipitation modeling, and (3) develop and validate a "fast-acting" spreadsheet approach that would enable a rapid means of predicting the important characteristics of the precipitate structure that evolves during cooling following solution treatment. The present paper delineates the research conducted to accomplish these goals. In particular, a suite of critical experiments and accompanying model development for the high-temperature (secondary-gammaprime) precipitation burst in the PM superalloy LSHR are summarized herein. In the future, additional ongoing work focusing on the lower-temperature precipitation behavior in this same alloy will be summarized.

\section{MATERIAL AND EXPERIMENTAL PROCEDURES}

\section{A. Material}

The PM superalloy LSHR (denoting "low-solvus, high refractory"), a material typical of multi-component gamma/gamma-prime superalloys used for high-temperature disk applications, was used to establish the details of on-cooling precipitation behavior and to develop and validate a corresponding fast-acting model. Originally developed by NASA, LSHR provides an attractive balance of properties at the bore and rim of disks that have been subjected to a graded-microstructure heat treatment in which only the component rim is exposed above the solvus temperature to promote local growth of the gamma grains. ${ }^{41,42]}$

The as-received material consisted of 230-mm-diameter extruded billet produced by Special Metals (Princeton, KY). This was the same material as that used in three previous investigations of the thermomechanical processing of LSHR. ${ }^{[3-45]}$ Its composition is given in Table I; its processing history is summarized in detail in the previous papers. In brief, the microstructure of the 
Table I. Composition (Atomic Percent) of Program Material

\begin{tabular}{lccccccccccc}
\hline & $\mathrm{Co}$ & $\mathrm{Cr}$ & $\mathrm{Al}$ & $\mathrm{Ti}$ & $\mathrm{Mo}$ & $\mathrm{W}$ & $\mathrm{Nb}$ & $\mathrm{Ta}$ & $\mathrm{C}$ & $\mathrm{B}$ & $\mathrm{Ni}$ \\
\hline LSHR $^{\prime}$ & 20.1 & 13.7 & 7.61 & 4.18 & 1.64 & 1.35 & 0.93 & 0.49 & 0.218 & 0.142 & Bal. \\
$\gamma^{\prime}$ in LSHR* & 11.2 & 2.11 & 12.0 & 7.86 & 0.75 & 1.24 & 1.61 & 0.96 & - & - & Bal. \\
\hline *Determined via phase extraction. ${ }^{[4]}$ & & & & & & & & \\
\hline
\end{tabular}

as-received LSHR comprised a fine, micro-duplex structure of gamma grains and gamma-prime precipitates, each of whose average diameter was $\sim 2 \mu \mathrm{m}$, and $\sim 0.33 \mathrm{vol}$ pct of uniformly-distributed carbide/boride particles with an average diameter of $315 \mathrm{~nm}$. The gamma-prime solvus, $\mathrm{T}_{\gamma^{\prime}}$, was $1430 \mathrm{~K}\left(1157^{\circ} \mathrm{C}\right)$.

\section{B. Experimental Procedures}

Two sets of heat-treatment experiments were performed to document the precipitation kinetics during continuous cooling of the LSHR program alloy. One set was done in a conventional laboratory environment, and the other in a high-energy, X-ray diffraction (synchrotron) facility.

\section{Laboratory experiments}

For the laboratory experiments, a series of bars, each measuring $10-\mathrm{mm}$ diameter $\times 90-\mathrm{mm}$ length, was extracted from the as-received billet via electric-discharge machining (EDM) followed by lathe turning to remove the recast layer. A small hole was drilled to the bar axis (at the mid-length position) into which a type-K thermocouple was inserted for temperature control. Individual bars were then heated via induction to a supersolvus temperature of $1463 \mathrm{~K}\left(1190{ }^{\circ} \mathrm{C}\right)$, soaked for 20 minutes to dissolve the gamma prime and homogenize the chemistry throughout the gamma grains (whose average diameter had grown to $\sim 20 \mu \mathrm{m}$ ), cooled at a rate of 11 or $139 \mathrm{~K} / \mathrm{min}\left(11\right.$ or $\left.139^{\circ} \mathrm{C} / \mathrm{min}\right)$, and then water quenched at a predetermined temperature within the range of $1089 \mathrm{~K}$ to $1411 \mathrm{~K}\left(816^{\circ} \mathrm{C}\right.$ to $\left.1138{ }^{\circ} \mathrm{C}\right)$. The chosen cooling rates bracket those typically experienced during heat treatment and minimize the tendency for quench cracking of full-scale components.

Following heat treatment, each bar was sectioned at the thermocouple location and prepared using standard metallographic procedures. Prior to imaging, samples were ion milled in a NOVA dual-beam, focused ion beam/scanning electron microscope (FIB/SEM) manufactured by FEI (Hillsboro, OR) to remove residual surface damage. For this purpose FIB milling was done in two stages, first with a high beam current (5000 pA) and then with a low beam current (500 pA). Intragranular precipitate structures were characterized using secondary-electron imaging (SEI) in an FEI Sirion SEM equipped with a field-emission gun. Approximately 20 images at magnifications between $5 \mathrm{~K}$ and $50 \mathrm{~K}$ were taken for each set of heat-treatment parameters. The test samples also exhibited precipitates at the gamma grain boundaries. Their overall volume fraction was small (less than 10 pct.). Because the focus of the present work was intragranular precipitation, the nature of the grainboundary precipitates is not reported herein.

For each set of test conditions, the intragranular precipitate area fraction, size, and number density were determined via two methods that gave similar results, i.e., (1) hand-painting followed by automated image analysis using FoveaPro ${ }^{\mathrm{TM}}$ software (Reindeer Graphics, Ashville, NC) and (2) a manual technique. The latter method consisted of point counting to determine the precipitate area fraction, $\mathrm{f}$, and the determination of the number of precipitates per unit area $\left(\mathrm{N}_{\mathrm{A}}\right)$. From these quantities, the average $2 \mathrm{D}$ circle-equivalent diameter (CED) of the precipitates was estimated.

The experimental error in the two-dimensional (2D) measurements comprised approximately \pm 0.02 for the area fraction and \pm 5 or \pm 10 pct of the reported values for the average precipitate size and number per unit area, respectively. The confounding influence of 2D measurements to quantify the complex three-dimensional (3D) precipitate morphologies developed under slower-cooling-rate conditions is described in Section IV-D.

The 2D precipitate measurements were converted to $3 \mathrm{D}$ quantities via standard stereological procedures ${ }^{[47,48]}$ to enable comparisons with model predictions. The volume fraction was taken to be equal to the $2 \mathrm{D}$ area fraction. To enable conversion of $2 \mathrm{D}$ sizes and number density, the precipitates were assumed to be mono-sized as an approximation. For spherical particles, for example, the average $3 \mathrm{D}$ diameter was taken to be equal to the CED times a factor of 1.225. For cuboidal particles of edge length $a$ (in 3D), the average 2D intercept area was taken to be equal to $2 \mathrm{a}^{2} / 3,{ }^{[47]}$ thus yielding a $3 \mathrm{D}$ diameter of 1.345 times CED for the sphere of equivalent volume to that of the cuboid. The number of precipitates per unit volume $\left(\mathrm{N}_{\mathrm{V}}\right)$ was determined from the following expression:

$$
\mathrm{N}_{\mathrm{V}}=(\mathrm{K} / \beta) \times\left(\mathrm{N}_{\mathrm{A}}\right)^{3 / 2} /(\mathrm{f})^{1 / 2}
$$

in which $\mathrm{K}$ denotes the size distribution coefficient (estimated to be 1.1 in the present work), and $\beta$ is a shape coefficient (equal to 1.38 or 1.84 for spherical or cuboidal precipitates, respectively). The average diameters of the equivalent spherical particles calculated from the $2 \mathrm{D}$ CED and the conversion factors of 1.225 or 1.345 , which are reported in Section IV, were approximately 5 pct higher than those determined from the measured area/ volume fraction and number per unit volume.

\section{Synchrotron experiments}

In-situ, X-ray-diffraction (XRD) experiments were conducted at the A2 beamline of the Cornell high-energy 
synchrotron source (CHESS) to provide further details on precipitation kinetics during cooling. For this purpose, sheet-like samples measuring $12.7 \times 152 \times 1 \mathrm{~mm}$ were prepared by EDM of strips from the LSHR billet, followed by surface grinding. Prior to testing, each sample was mounted in a quartz tube (through which high-purity argon was passed) that was situated within a custom-built, indirect-resistance furnace containing holes for passage of the incident and diffracted X-ray beams. For most of the tests, preheating and cooling parameters were identical to those summarized in Section II-B-1 on the laboratory experiments. Additional trials were conducted to estimate the approximate degree of supersaturation retained during cooling. For these experiments, samples were supersolvus preheated, soaked, continuously cooled to $1340 \mathrm{~K}\left(1067{ }^{\circ} \mathrm{C}\right)$, and then held for 30 minutes to determine changes in the $\mathrm{X}$-ray signal which would be indicative of the change in precipitate volume fraction. During all experiments, XRD data were collected using a GE 41RT amorphous-silicon detector (manufactured by GE Healthcare). The (100) peak of the gamma-prime phase was used to delineate nucleationand-growth behavior and the retained supersaturation. Further details on experimental procedures and an indepth summary of the in situ XRD results are contained in a companion paper. ${ }^{[49]}$

\section{EXPERIMENTAL RESULTS}

The principal results of this work comprised SEM observations of the precipitates developed during continuous cooling following supersolvus solution treatment, quantitative measurements of the precipitate area fraction, average size, and number density, and in situ XRD measurements of the evolution of the gammaprime phase.

\section{A. Precipitation Observations}

SEM SEI characterization revealed a noticeable dependence of intragranular precipitate formation on cooling rate and interrupted-cooling quench temperature $T_{\mathrm{q}}$ (Figures 1, 2 for a cooling rate of $139 \mathrm{~K} / \mathrm{min}$ $\left(139{ }^{\circ} \mathrm{C} / \mathrm{min}\right)$ and Figure 3 for a cooling rate of $\left.11 \mathrm{~K} / \mathrm{min}\left(11^{\circ} \mathrm{C} / \mathrm{min}\right)\right)$.

Focusing first on the results for the faster cooling rate (Figures 1, 2), samples water quenched from the solution temperature of $1463 \mathrm{~K}\left(1190{ }^{\circ} \mathrm{C}\right)$ (e.g., Figure 1(a)) exhibited a uniform distribution of extremely-fine gamma-prime precipitates whose area fraction was high. This observation suggested that the cooling rate associated with water quenching per se was not high enough to eliminate the formation of fine precipitates at low temperatures due to the high supersaturation which was developed. A sample which was supersolvus solution treated, cooled at $139 \mathrm{~K} / \mathrm{min}\left(139^{\circ} \mathrm{C} / \mathrm{min}\right)$, and water quenched upon reaching a temperature lying $\sim 20 \mathrm{~K}$ $\left(20^{\circ} \mathrm{C}\right)$ below the solvus (i.e., $1411 \mathrm{~K}$, or $1138{ }^{\circ} \mathrm{C}$ ) showed a very similar microstructure (Figure 1(b)). Thus, it may be surmised that the associated undercooling had not produced precipitate nucleation at that temperature. By contrast, an undercooling of $\sim 40 \mathrm{~K}$ $\left(\sim 40{ }^{\circ} \mathrm{C}\right)$ led to a modest volume fraction of approximately spheroidal (secondary-gamma-prime) precipitates that were considerably coarser than those produced in water-quenched samples that had been solution treated or solution treated and given a small undercooling (Figure 1(c) vs (a), (b)). At yet larger levels of undercooling, the size and area fraction of the precipitates increased, but their approximately spheroidal shape did not undergo major changes (Figures 1(d), 2).

The microstructures developed in samples that were solution treated and then cooled at the slower rate $\left(11 \mathrm{~K} / \mathrm{min}\right.$, or $\left.11^{\circ} \mathrm{C} / \mathrm{min}\right)$ were qualitatively similar, but showed some noticeable differences (Figure 3). As for the faster cooling rate, precipitate nucleation during slower cooling was absent at an undercooling of $\sim 20 \mathrm{~K}$ $\left(20^{\circ} \mathrm{C}\right)$ (not shown), but was evident for an undercooling of $\sim 40 \mathrm{~K}\left(40{ }^{\circ} \mathrm{C}\right)$ (Figure $3(\mathrm{a})$ ). The precipitates formed at the $40 \mathrm{~K}\left(40{ }^{\circ} \mathrm{C}\right)$ undercooling tended to be noticeably cuboidal in $2 \mathrm{D}$ sections. In samples cooled further (i.e., to $1366 \mathrm{~K}$, or $1093^{\circ} \mathrm{C}$ ), a number of the cuboidal particles appeared to have experienced classical morphological instability ${ }^{[50]}$ during their growth as indicated by matrix-precipitate interface waviness and/ or the formation of dendritic-like features (sometimes denoted as "cauliflower" in shape); examples are indicated by the arrows in Figure 3(b). Such features appear to be analogous to irregularities observed in 3D by MacSleyne et al. ${ }^{[1]}$

With further cooling at the slower rate, the secondarygamma-prime precipitates grew substantially larger (Figures 3(c) through (f)). Because of the coarseness and irregular precipitate shape that appeared to develop, it was difficult to determine from the $2 \mathrm{D}$ observations whether collections of discrete adjacent particles were actually associated with one or several precipitates or if precipitate impingement and coalescence had occurred. These possibilities are now being investigated via an automated serial-sectioning technique. Despite such difficulties, higher magnification secondary-electron images did show that tertiary gamma-prime precipitates had formed by the time a temperature of $1089 \mathrm{~K}$ $\left(816^{\circ} \mathrm{C}\right)$ had been reached (Figure 3(f)).

\section{B. Quantitative Precipitate Data}

The intragranular, secondary gamma-prime precipitation results illustrated by the micrographs in Figures 1 to 3 were quantified in terms of area fraction, 2D circleequivalent diameter (CED), and number per unit area (Figure 4).

The dependence of area fraction on instantaneous temperature was similar for both cooling rates (Figure 4(a)). The area fraction grew very rapidly at high temperatures and much more slowly as the temperature decreased. This trend followed approximately the equilibrium solvus-approach curve based on experimental data which is cross-plotted in the figure. At a temperature of $\sim 1200 \mathrm{~K}\left(\sim 927^{\circ} \mathrm{C}\right)$, the data started to diverge from the solvus-approach curve. This behavior suggested limited further growth of the secondary gamma- 

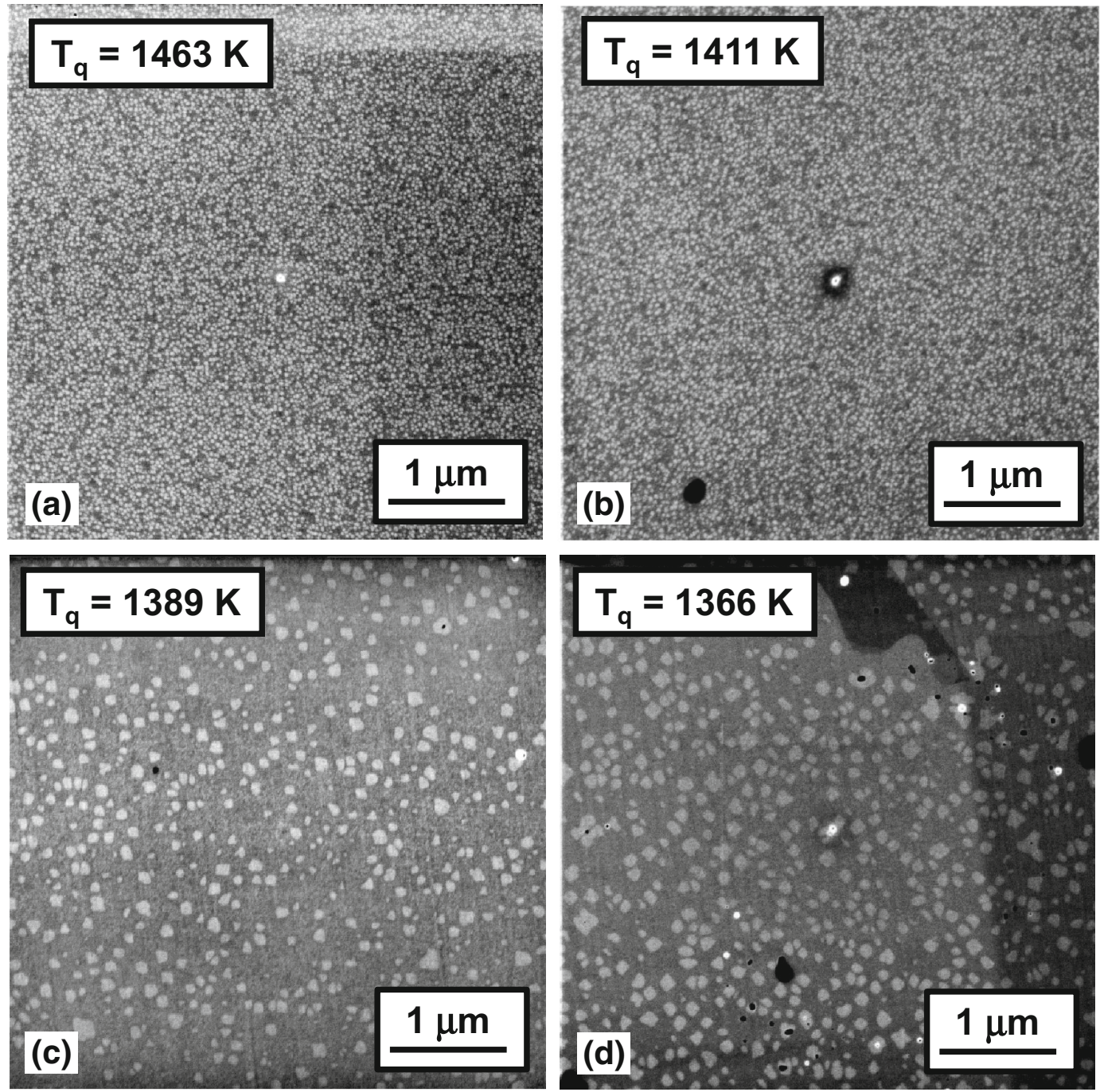

Fig. 1-Micrographs of gamma-prime precipitates formed in LSHR samples that were $(a)$ solution-treated at $1463 \mathrm{~K}\left(1190{ }^{\circ} \mathrm{C}\right)$ and then water quenched or $\left(b\right.$ through $d$ ) solution treated, cooled at $139 \mathrm{~K} / \mathrm{min}\left(139^{\circ} \mathrm{C} / \mathrm{min}\right)$, and water quenched at various temperatures $T_{\mathrm{q}}$ lying approximately $20 \mathrm{~K}$ to $65 \mathrm{~K}\left(20^{\circ} \mathrm{C}\right.$ to $\left.65^{\circ} \mathrm{C}\right)$ below the gamma-prime solvus.

prime precipitates. As will be discussed in Section IV, this restrained growth can be rationalized in terms of the reduced diffusivity and large radius of secondarygamma-prime particles at lower temperatures and the depletion of matrix supersaturation by the nucleation of tertiary gamma-prime precipitates.

The diameter and number density measurements for the secondary-gamma-prime precipitates (Figures 4(b), (c)) mirrored the area-fraction trends. In particular, the average CED indicated rapid growth at high temperatures and then slow or negligible particle growth with decreasing temperature. Furthermore, the fact that the number density changed little with decreasing temperature below $\sim 1385 \mathrm{~K}\left(\sim 1112{ }^{\circ} \mathrm{C}\right)$ suggested that nucleation occurred over a relatively-narrow temperature range between this temperature and the solvus, and, hence, the increase in area fraction with decreasing temperature resulted primarily from particle growth rather than additional nucleation. More quantitative interpretation of these results in terms of the $3 \mathrm{D}$ size of the precipitates and number per unit volume is given in Section IV.

\section{In-Situ XRD Observations}

Additional information on the temperature at which gamma prime nucleated during cooling and the level of retained supersaturation was gleaned from the in situ XRD measurements (Figure 5). Based on the initial rise in the intensity of the (100) peak of the gamma-prime phase (relative to the background intensity), nucleation of a measurable fraction of gamma prime occurred at $1403.5 \mathrm{~K}\left(1130.5^{\circ} \mathrm{C}\right)$ (Figure 5(a)). This value is essentially identical to that determined by a mechanicaltesting method ${ }^{[52]}$ in which an observed (discontinuous) jump in flow stress during concurrent plastic straining and cooling (at identical rates to those used in the present work) was taken to be indicative of the onset of nucleation. It is also of interest to note that the present determination is only $\sim 5 \mathrm{~K}\left(\sim 5^{\circ} \mathrm{C}\right)$ higher than the 

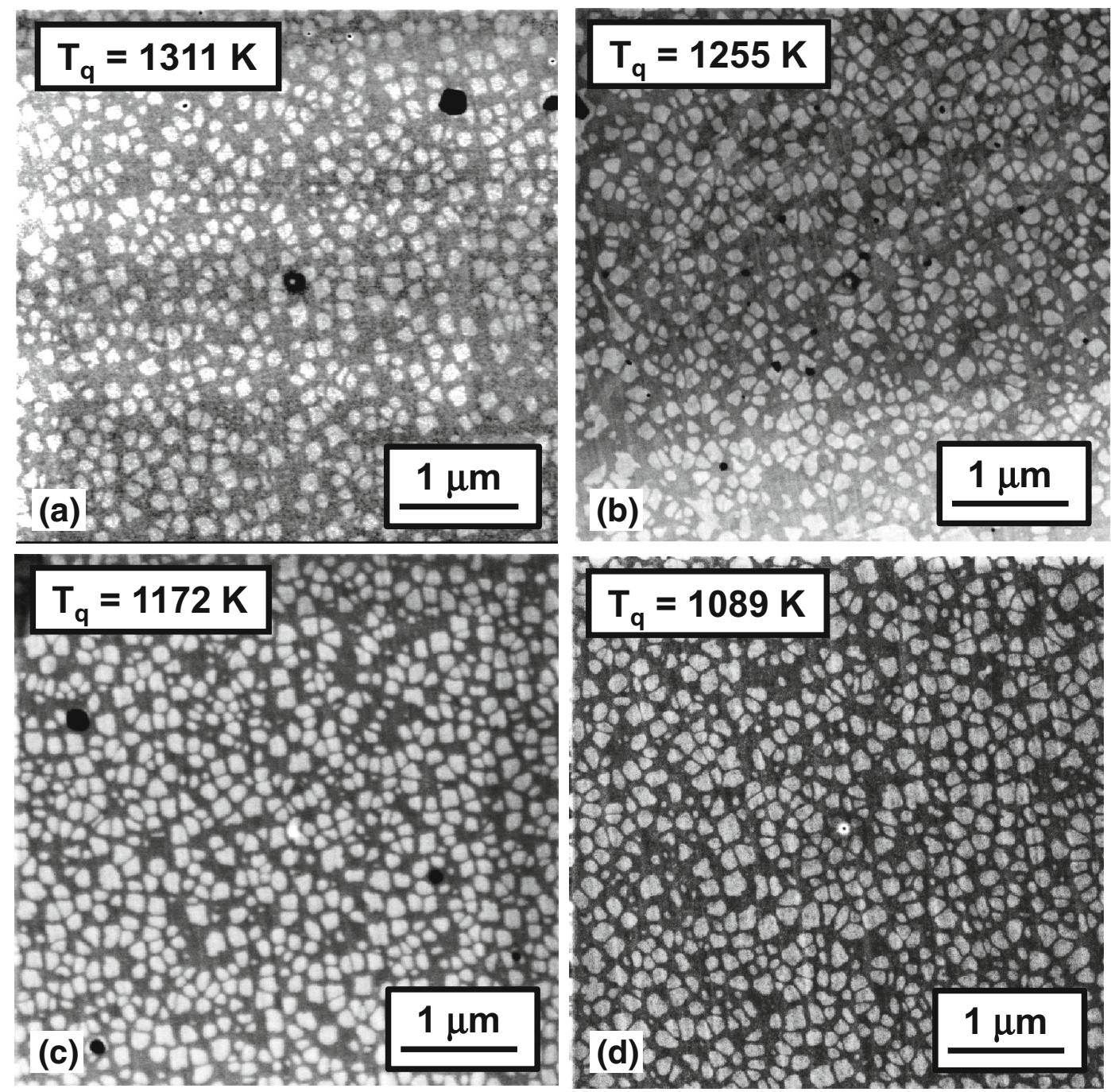

Fig. 2-Micrographs of gamma-prime precipitates formed in LSHR samples that were solution treated, cooled at $139 \mathrm{~K} / \mathrm{min}\left(139{ }^{\circ} \mathrm{C} / \mathrm{min}\right)$, and water quenched at various temperatures $T_{\mathrm{q}}$ lying approximately $120 \mathrm{~K}$ to $340 \mathrm{~K}\left(120^{\circ} \mathrm{C}\right.$ to $\left.340{ }^{\circ} \mathrm{C}\right)$ below the gamma-prime solvus.

values determined by single-sensor differential thermal analysis (SSDTA) for much higher cooling rates (i.e., $\sim 3600 \mathrm{~K} / \mathrm{min}$, or $\left.3600{ }^{\circ} \mathrm{C} / \mathrm{min}\right) .\left[{ }^{38]}\right.$

Synchrotron experiments comprising continuous cooling with a 30 -minute hold at $1340 \mathrm{~K}\left(1067^{\circ} \mathrm{C}\right)$ suggested that a measurable supersaturation was retained during the cooling cycle. Specifically, for a cooling rate of $11 \mathrm{~K} / \mathrm{min}\left(11^{\circ} \mathrm{C} / \mathrm{min}\right)$, the approximate difference in the volume fraction of gamma-prime precipitate just prior to and at the end of the hold period was $\sim 6$ pct of the latter (assumed equilibrium) amount (Figure 5(b)).

The application of the XRD data for model development and validation is described in Section IV.

\section{PRECIPITATION MODELING}

The experimental observations were used to develop and validate a fast-acting model to describe intragranular precipitation in gamma/gamma prime superalloys during continuous cooling. In the following sub-sections, the rudiments of the model formulation, methods used to obtain the input material properties for the model, the simulation approach, and model validation via comparison to experimental measurements are described.

\section{A. Model Formulation}

The model formulation was based on classical relations for the rate of homogeneous nucleation, diffusional growth, and static coarsening.

\section{Nucleation rate}

The rate of nucleation of precipitates, $\mathrm{J}$, was given by the following equation ${ }^{[4,12,26]}$ :

$$
\begin{aligned}
\mathbf{J} & =\frac{2 \mathrm{CD}}{\mathrm{a}_{\mathrm{o}}^{4}} \sqrt{\frac{\sigma}{\mathrm{k}_{\mathrm{B}} \mathrm{T}}} \cdot \exp \left(-\frac{4 \pi \sigma \mathrm{r} *^{2}}{3 \mathrm{k}_{\mathrm{B}} \mathrm{T}}\right) \cdot \exp (-\tau / \mathrm{t}) \\
& =\mathbf{J}_{\mathrm{o}} \exp (-\tau / \mathrm{t}),
\end{aligned}
$$

in which $\mathrm{C}$ denotes the solute content in the matrix expressed as an atomic fraction, D is the solute 

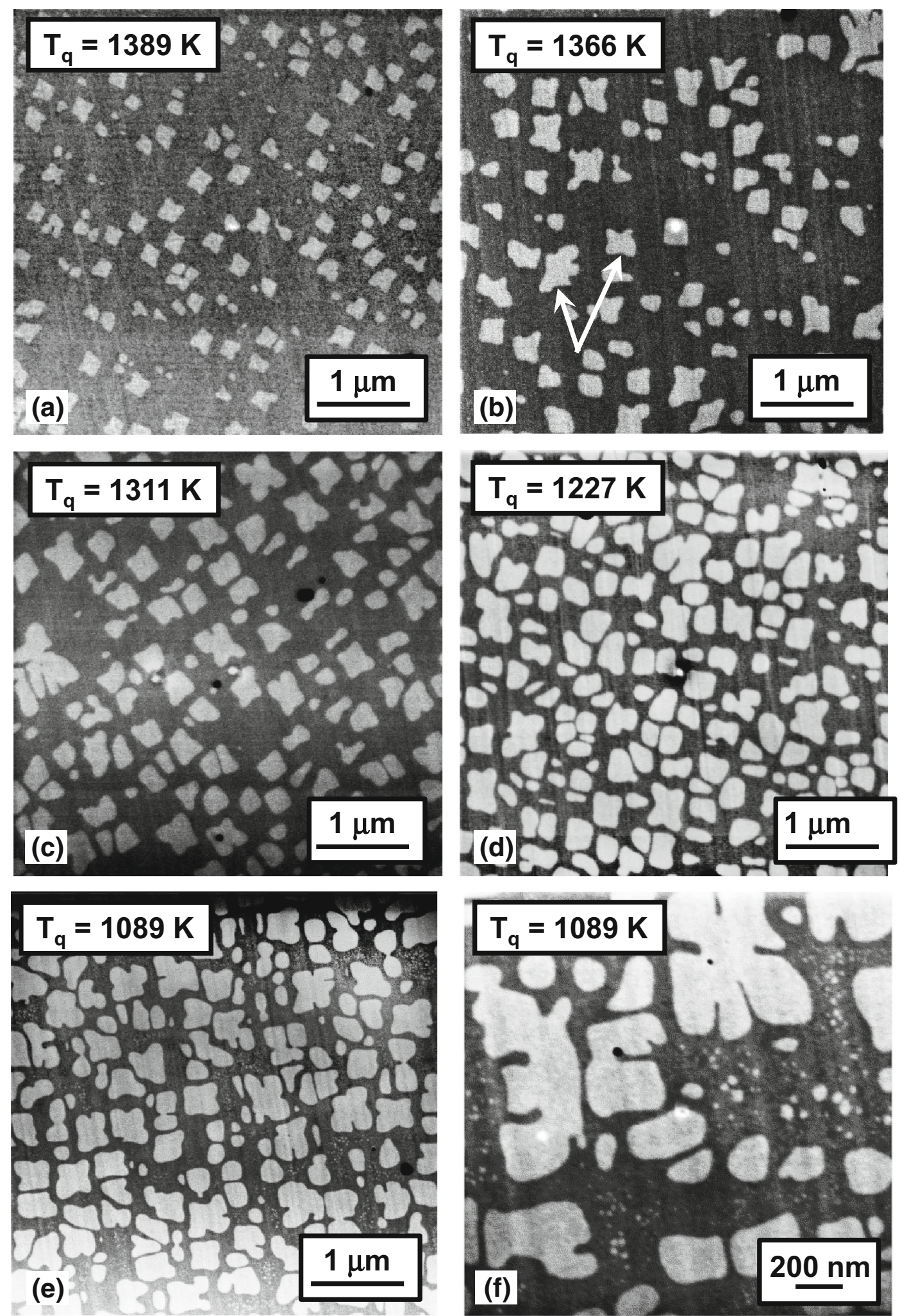

Fig. 3-Micrographs of gamma-prime precipitates formed in LSHR samples that were solution treated, cooled at $11 \mathrm{~K} / \mathrm{min}\left(11^{\circ} \mathrm{C} / \mathrm{min}\right)$, and water quenched at various temperatures $T_{\mathrm{q}}$ lying approximately $40 \mathrm{~K}$ to $340 \mathrm{~K}\left(40{ }^{\circ} \mathrm{C}\right.$ to $\left.340{ }^{\circ} \mathrm{C}\right)$ below the gamma-prime solvus.

diffusivity in the matrix phase, $\mathrm{a}_{\mathrm{o}}$ is the average lattice parameter of the matrix and precipitate phases (taken to be $0.356 \mathrm{~nm}), \sigma$ is the matrix-precipitate surface energy, $\mathrm{k}_{\mathrm{B}}$ is Boltzmann's constant $\left(1.3806 \mathrm{JK}^{-1}\right)$, $\mathrm{T}$ is temperature in kelvins, and $\mathrm{t}$ is time. The critical radius of the precipitate, $\mathrm{r}^{*}$, is related to $\sigma$, the chemical 


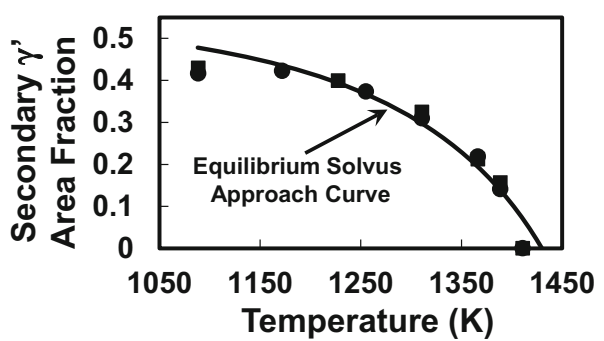

(a)

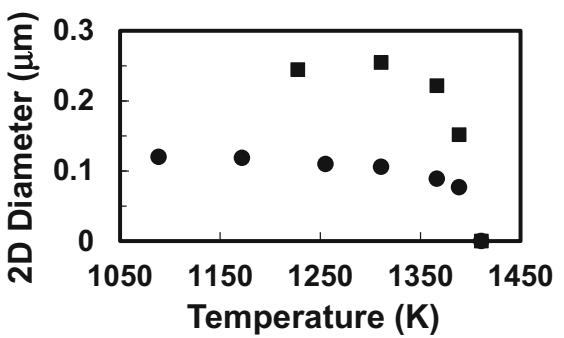

(b)

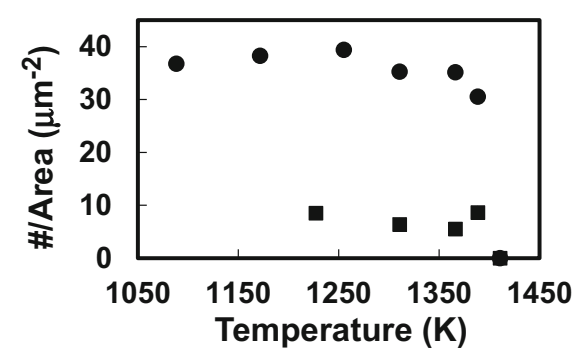

(c)

Fig. 4-Experimental data for secondary gamma-prime precipitates formed in LSHR as a function of temperature and a cooling rate (in $\mathrm{K} / \mathrm{min}$ ) of 139 (circles) or 11 (squares): $(a)$ area fraction, $(b)$ average 2D diameter, and (c) number per unit area. The results in (a) are compared to measurements of the equilibrium solvus approach curve.

free energy of transformation, $\Delta \mathrm{G}^{*}$, and the elastic strain energy, $\Delta \mathrm{G}_{\mathrm{p}}$, associated with the difference in lattice parameters of the matrix and precipitate phases, i.e.,

$$
\mathrm{r}^{*}=\frac{2 \sigma}{\Delta \mathrm{G}^{*}+\Delta \mathrm{G}_{\mathrm{p}}}
$$

The nucleation rate $\mathbf{J}$ in Eq. [2] is related to the steady-state nucleation rate $J_{o}$ through the term $\exp (-\tau / \mathrm{t})$, which describes the initial nucleation transient during which a metastable distribution of embryos with sub-critical radii are formed. The so-called incubation time constant $\tau$ in this exponential term is given by the relation ${ }^{[26,53]}$ :

$$
\tau=\frac{\pi \mathrm{RTr} *^{3}}{96 \mathrm{~V}_{\mathrm{M}} \mathrm{D} \sigma}
$$

in which $\mathrm{R}$ is the gas constant, and $\mathrm{V}_{\mathrm{M}}$ is the molar volume of the precipitate.

Strictly speaking, Eqs. [2] through [4] apply to nucleation in two-component alloys. In the present work, methods and

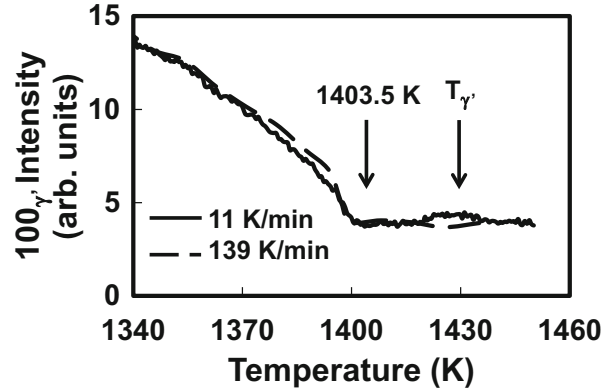

(a)

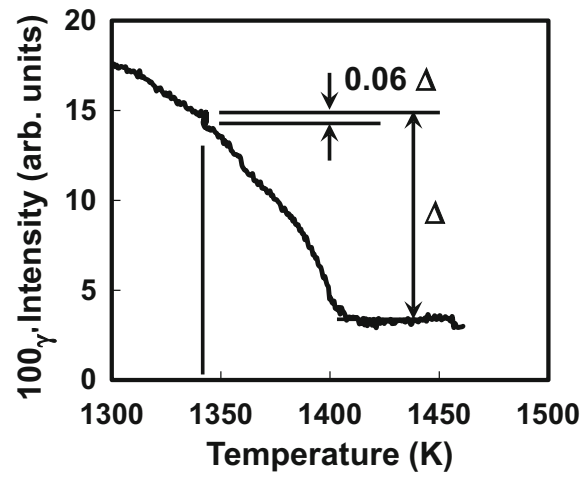

(b)

Fig. 5-In-situ, XRD data for the (100), peak illustrating precipitation behavior during cooling of LSHR: (a) Precipitation-nucleation temperature and $(b)$ effect of 30 -minute hold at $1338 \mathrm{~K}\left(1065^{\circ} \mathrm{C}\right)$ during cooling at $11 \mathrm{~K} / \mathrm{min}\left(11^{\circ} \mathrm{C} / \mathrm{min}\right)$ on intensity level.

assumptions utilized to determine effective values for coefficients such as $\mathrm{C}, \mathrm{D}$, and $\Delta \mathrm{G}^{*}$ of multi-component alloys for use in the nucleation (as well as growth and coarsening) relations are described in Section IV-B.

\section{Diffusional growth}

The precipitates were assumed to be spherical of radius $\mathrm{r}$ with their growth controlled by diffusion. The "exact" solution of the diffusion equation ${ }^{[13,14]}$ for the rate of growth in the presence of a finite matrix supersaturation was used, i.e.,

$$
\mathrm{dr} / \mathrm{dt}=2 \lambda^{2} \mathrm{D} / \mathrm{r},
$$

in which $\lambda^{2}$ is related to the supersaturation $\Omega$ by the following expression:

$$
\left\{\lambda^{2} \exp \left(\lambda^{2}\right)\right\} \cdot\left[\left(\exp \left(-\lambda^{2}\right)\right)-\left(\lambda \pi^{1 / 2} \operatorname{erfc}(\lambda)\right)\right]=\Omega / 2 .[6]
$$

The supersaturation $\Omega$ had its usual definition, i.e.,

$$
\Omega=\left(\mathrm{C}_{\mathrm{m}}-\mathrm{C}_{\mathrm{i}}\right) /\left(\mathrm{C}_{\mathrm{p}}-\mathrm{C}_{\mathrm{i}}\right) .
$$

Here, $C_{m}, C_{i}$, and $C_{p}$ represent the compositions of the matrix far from the matrix-particle interface, the matrix at the matrix-particle interface, and the particle at the matrix-particle interface, respectively. The correction to the equilibrium $(r=\infty)$ interface composition, $\mathrm{C}_{\mathrm{i}}$, due to the Gibbs-Thompson effect was quantified using the following expression ${ }^{[54]}$. 


$$
\mathrm{C}_{\mathrm{i}}(\mathrm{r})=\mathrm{C}_{\mathrm{i}}(\mathrm{r}=\infty)\left(1+\frac{2\left(1-\mathrm{C}_{\mathrm{m}}\right) \sigma \mathrm{V}_{\mathrm{M}}}{\left(\mathrm{C}_{\mathrm{p}}-\mathrm{C}_{\mathrm{m}}\right) \mathrm{RTr}}\right) .
$$

The effect of soft impingement on the 'far-field' matrix composition $\mathrm{C}_{\mathrm{m}}$ was taken into account using the usual approximation derived from a mass balance $^{[55]}$.

$$
\mathrm{C}_{\mathrm{m}}=\left(\mathrm{C}_{\mathrm{o}}-\mathrm{fC}_{\mathrm{p}}\right) /(1-\mathrm{f}),
$$

in which $\mathrm{C}_{\mathrm{o}}$ and $\mathrm{f}$ denote the overall alloy composition and the volume fraction of the precipitate. In the present work, it was assumed that the composition of the gamma-prime precipitate was constant and equal to the average value determined by phase extraction (Table I).

\section{Coarsening}

The tendency for measurable coarsening of the secondary gamma-prime precipitates was small due to retained supersaturation during continuous cooling and the narrow particle size distribution developed during nucleation. Nevertheless, the specific rate of increase of the average precipitate size was assessed using the modified LSW theory $(15,16,21)$ embodied by the following equations:

$$
\begin{gathered}
\text { and } \mathrm{K}_{\mathrm{MLSW}}=\frac{8 \mathrm{w}(\phi) \mathrm{D} \sigma \mathrm{C}_{\gamma}\left(1-\mathrm{C}_{\gamma}\right) \mathrm{V}_{\mathrm{M}}^{3}=\mathrm{K}_{\mathrm{MLSW}}}{9 \mathrm{RT}\left(\mathrm{C}_{\gamma^{\prime}}-\mathrm{C}_{\gamma}\right)^{2}\left[1+\partial \operatorname{lnv} / \partial \ln \mathrm{C}_{\gamma}\right]} .
\end{gathered}
$$

In Eq. [10], $\overline{\mathrm{r}}$ and $\overline{\mathrm{r}}_{\mathrm{o}}$ represent the average instantaneous and initial particle radii. In the expression for the modified LSW rate constant, KMLSW, terms not previously defined include $\mathrm{w}(\phi)$, the factor to correct for the finite volume fraction of particles, ${ }^{[17-20]}$ and $\mathrm{C}_{\gamma}$ and $\mathrm{C}_{\gamma^{\prime}}$, the equilibrium concentrations of the ratelimiting solute in the matrix and precipitate, respectively. The bracketed term in the denominator of Eq. [11] is the thermodynamic factor in which $v$ denotes the activity coefficient for the rate-limiting solute in the gamma matrix.

\section{B. Input Data for Model}

The input data for modeling precipitation in LSHR consisted of the molar volume $\left(\mathrm{V}_{\mathrm{M}}\right)$, the solute composition in the matrix (C), $\Delta \mathrm{G}^{*}, \Delta \mathrm{G}_{\mathrm{p}}, \sigma$, and $\mathrm{D}$. The molar volume was determined to be $7.22 \times 10^{-6} \mathrm{~m}^{3}$ from the gramatomic weight of the secondary gamma prime in LSHR $(58 \mathrm{~g})$ and its approximate density $\left(8.03 \times 10^{3} \mathrm{~kg} / \mathrm{m}^{3}\right)$.

For LSHR, the total solute content during solution treatment in the single-phase gamma field is $\sim 0.5$. As suggested by the results in Section III (which were mirrored by model simulations in Section IV-C), the majority of the secondary-gamma-prime nuclei formed during a short time interval during which the matrix composition underwent little change. Hence, it was assumed that the value of $\mathrm{C}$ in Eq. [2] remained constant. However, the sensitivity of the predicted number of nuclei to the specific value of $\mathrm{C}$ was assessed and is summarized in Section IV-D.

The determination of the other input parameters was somewhat more difficult, and their derivation is therefore discussed individually in the following sub-sections.

\section{1. $\Delta G^{*}$}

Two different methods were used to determine the chemical free energy change associated with the formation of gamma prime from a supersaturated gamma matrix, i.e., $\Delta \mathrm{G}^{*}$. One was based on measurements of the specific heat and knowledge of the equilibrium solvus temperature; the other involved a thermodynamic calculation based on a pseudo-binary of nickel and chromium.

The first technique focused on $\Delta \mathrm{G}^{*}$ for the matrix composition pertaining to the (supersolvus) solution temperature, i.e., the overall alloy composition. The enthalpy $\left(\Delta \mathrm{H}_{\mathrm{avg}}\right)$ and entropy $\left(\Delta \mathrm{S}_{\mathrm{avg}}\right)$ of formation (per mol) were assumed to be constant, and thus $\Delta \mathrm{G}^{*}$ varied linearly with temperature

$$
\Delta \mathrm{G}^{*}\left(\gamma \rightarrow \gamma^{\prime}\right)=\Delta \mathrm{H}_{\mathrm{avg}}-\mathrm{T} \Delta \mathrm{S}_{\mathrm{avg}} .
$$

The enthalpy of formation was determined by integrating "adjusted" values of measured specific heat $\mathrm{C}_{\mathrm{P}}{ }^{[56]}$ over the transformation range $(\sim 1410 \mathrm{~K} \rightarrow$ $1144 \mathrm{~K}$, or $1137^{\circ} \mathrm{C} \rightarrow 871^{\circ} \mathrm{C}$ ) for a sample which had been cooled at a rate of $20 \mathrm{~K} / \mathrm{min}\left(20^{\circ} \mathrm{C} / \mathrm{min}\right)$ following supersolvus solution treatment (Figure 6(a)). The adjustment factor consisted of a "baseline" connecting the low and high temperature regimes in which essentially no transformation had occurred. Knowledge of the fraction transformed ( $\mathrm{f}=0.42$ ) gave the desired quantity:

$$
\Delta \mathrm{H}_{\mathrm{avg}}=\left(\int \mathrm{C}_{\mathrm{P}} \mathrm{T}\right) / 0.42=7205 \mathrm{~J} / \mathrm{mol} .
$$

At the gamma-prime solvus $\left(1430 \mathrm{~K}\right.$, or $\left.1157^{\circ} \mathrm{C}\right)$, the value of $\Delta \mathrm{G}^{*}$ is equal to zero. From Eq. [12], $\Delta \mathrm{S}_{\text {avg }}$ was thus found to be $5.04 \mathrm{~J} / \mathrm{molK}$. For matrix compositions $\mathrm{C}_{\mathrm{m}}$ not equal to that pertaining to the composition during supersolvus solution treatment, the value of $\Delta \mathrm{G}^{*}$ was estimated by correlating it to the instantaneous value of $\mathrm{C}_{\mathrm{m}}-\mathrm{C}_{\mathrm{e}}$, in which $\mathrm{Ce}$ denotes the equilibrium matrix composition.

The second approach used to quantify $\Delta \mathrm{G}^{*}$ was based on the following expression from solution thermodynamics $^{[4]}$ :

$$
\Delta \mathrm{G}^{*}\left(\gamma \rightarrow \gamma^{\prime}\right)=-\frac{\left(\mathrm{C}_{\gamma^{\prime}}-\mathrm{C}_{\gamma}\right) \mathrm{RT} \ln \left(\mathrm{C}_{\gamma} / \mathrm{C}_{\mathrm{m}}\right)}{\left(1-\mathrm{C}_{\gamma}\right)\left[1+\partial \ln \mathrm{v} / \partial \ln \mathrm{C}_{\gamma}\right]},
$$

in which all of the terms were defined in Section IV-A. Values of $\Delta \mathrm{G}^{*}$ as a function of temperature were calculated from Eq. [14] for a series of pseudobinary alloys of nickel and the solutes in LSHR (Table I). Initial calculations assumed that the matrix solute composition $\left(\mathrm{C}_{\mathrm{m}}\right)$ was equivalent to that for a supersolvus solution treatment and the (equilibrium) gamma-prime-precipitate composition $\left(\mathrm{C}_{\gamma^{\prime}}\right)$ was constant 


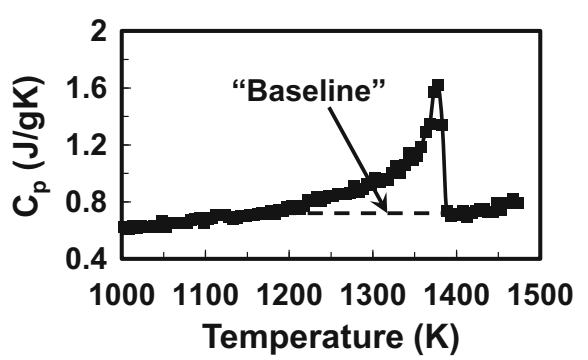

(a)

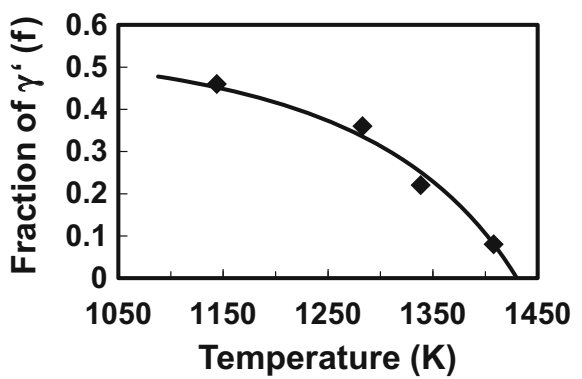

(b)

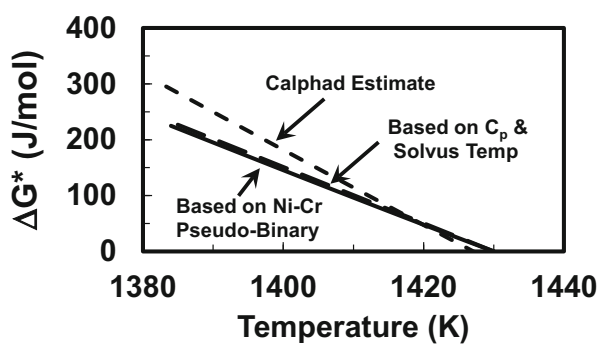

(c)

Fig. 6-Determination of the Gibbs free energy of transformation, $\Delta \mathrm{G}^{*}$ : (a) On-cooling specific heat, ${ }^{[56]}$ (b) equilibrium gamma-prime solvus approach curve (data points = measurements), and (c) comparison of $\Delta G^{*}$ determined by the specific heat, Ni-Cr pseudo-binary, and Calphad methods.

(per the values in Table I). The equilibrium solute composition in the matrix was determined from the precipitate composition and the equilibrium volume fraction of gamma-prime per the solvus approach curve (f(T)) for LSHR (Figure 6(b)), which had been determined via quantitative metallography on samples that were isothermally forged and/or heat treated for long times. To simplify these calculations, the $\mathrm{f}(\mathrm{T})$ measurements were fitted to an analytical expression suggested by Payton, ${ }^{[57]}$ i.e.,

$$
f=-\frac{4 \mathrm{C}^{*}\left(1-\exp \left[\frac{\mathrm{Q}}{\mathrm{R}}\left(\frac{\mathrm{T}-\mathrm{T}_{\gamma^{\prime}}}{\mathrm{T} \times \mathrm{T}_{\gamma^{\prime}}}\right)\right]\right)}{1-4 \mathrm{C}^{*} \exp \left[\frac{\mathrm{Q}}{\mathrm{R}}\left(\frac{\mathrm{T}-\mathrm{T}_{\gamma^{\prime}}}{\mathrm{T} \times \mathrm{T}_{\gamma^{\prime}}}\right)\right]} .
$$

Here, $\mathrm{C}^{*}$ denotes the atomic fraction of gamma-prime formers in the alloy $(\sim 0.535$ for LSHR), and $\mathrm{Q}$ is a fitting parameter $(=60 \mathrm{~kJ} / \mathrm{mol})$ (Figure 6(b)).

The thermodynamic factor for chromium in LSHR was estimated to be $1.2 ;^{[58]}$ this factor for the other solutes lay in the range between 1 and 2. Calculations based on Eq. [14] for the various solutes revealed that the Ni-Cr pseudo-binary gave the largest absolute value of $\Delta \mathrm{G}^{*}$, being a factor of two or more greater than that for other solutes. This observation is largely a result of the much greater partitioning of this alloying element between the matrix and precipitate phases for LSHR. Hence, it was assumed that a $\mathrm{Ni}-\mathrm{Cr}$ pseudo-binary approach was most appropriate for modeling $\Delta \mathrm{G}^{*}$.

Comparison of the values of $\Delta \mathrm{G}^{*}$ (for a supersaturated matrix of the supersolvus-solutioned composition) obtained by the two different approaches revealed excellent agreement (Figure 6(c)). However, such values differed somewhat from that derived from a Calphad approach for the same matrix composition. ${ }^{[59]}$

Because of its relative simplicity and ease of application for arbitrary matrix compositions, Eq. [14] was used for the majority of the nucleation calculations.

\section{2. $\Delta G_{p}$}

As a first approximation, the value $\Delta \mathrm{G}_{\mathrm{p}}$ was taken to be small relative to that of $\Delta G^{*}$ and neglected in the present work. This assumption was based on the work of Booth-Morrison et al. ${ }^{[60]}$ for a ternary Ni-Cr-Al alloy (with levels of chromium and aluminum similar to that in LSHR), which exhibited negligible misfit. Even with a lattice-parameter misfit of $\sim 0.2$ pct., $\Delta \mathrm{G}_{\mathrm{p}}$ would be of the order of $7 \mathrm{~J} / \mathrm{mol}$ due to the mitigating influence of low shear (and bulk) moduli of LSHR at $1400 \mathrm{~K}$ $\left(1127^{\circ} \mathrm{C}\right) .{ }^{[56]}$ Such a value is more than an order of magnitude smaller than the values of $\Delta \mathrm{G}^{*}$ for temperatures at which secondary gamma-prime nucleation occurs in LSHR. The measurement of the high-temperature lattice parameters of the free-standing gamma and gamma-prime phases in this alloy is needed, however, to verify the applicability of this assumption.

\section{Surface energy, $\sigma$}

The choice of surface energy was based on the temperature at which noticeable nucleation occurred, i.e., $1403.5 \mathrm{~K}\left(1130.5^{\circ} \mathrm{C}\right)$. Using an approach similar to that suggested by Doherty, ${ }^{[4]}$ the surface energy was chosen to produce a value of $\mathrm{J}_{\mathrm{O}}$ (per Eq. [2] with a diffusivity selected per the discussion in Section IV-B-3) of $1 / \mu \mathrm{m}^{3} \mathrm{~s}\left(10^{18} / \mathrm{m}^{3} \mathrm{~s}\right)$ at this temperature (Figure 7$)$. The surface energy so deduced was $23 \mathrm{~mJ} / \mathrm{m}^{2}$. Because of its exponential dependence on $\sigma^{3}$, the use of a different value for the 'critical' value of $\mathbf{J}$ would have led to only a small difference in the choice of $\sigma$. For example, if the critical $\mathbf{J}$ were chosen to be $0.1 / \mu \mathrm{m}^{3} \mathrm{~s}$, the surface energy would have been $24 \mathrm{~mJ} / \mathrm{m}^{2}$ per the plot in Figure 7.

The value of $\sigma$ found in the present work is almost identical to that deduced by Sudbrack et al. ${ }^{[29]}$ for a ternary Ni-Al-Cr alloy with levels of aluminum and chromium similar to those in LSHR. By contrast, the present value is considerably lower than the value quoted by Olson et al. ${ }^{[38]}$ for LSHR, i.e., $31.5 \mathrm{~mJ} / \mathrm{m}^{2}$. Perhaps, such a difference can be rationalized in the context of values of $\Delta G^{*}$ which may have been high in the earlier prior work.

\section{Diffusivity, $D$}

The diffusivity plays a very important role in the precipitation process through its effect on particle 


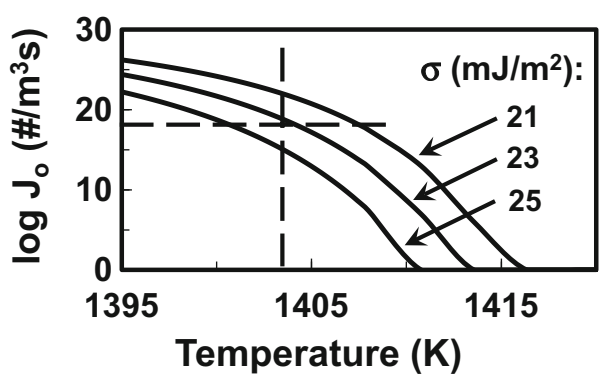

Fig. 7-Dependence of the predicted steady-state nucleation rate $\left(\mathrm{J}_{\mathrm{o}}\right)$ from Eq. [2] on temperature for several values of surface energy $\sigma$.

growth, which, in turn, affects the rate of depletion of the matrix supersaturation controlling nucleation behavior. Because alloying elements such as $\mathrm{Al}$ and $\mathrm{Ti}$ partition in a sense opposite to that of $\mathrm{Cr}$ in the gamma and gamma-prime phases and the presence of finite offdiagonal terms in the diffusivity matrix, the development of a concentration gradient for one alloying element may noticeably retard the overall diffusion of another. For example, $\mathrm{Al}$ and $\mathrm{Cr}$ in a nickel solid solution have a positive interaction such that $\mathrm{Al}$ can diffuse down a chromium concentration gradient. ${ }^{[61-63]}$ Thus, as a gamma-prime precipitate grows, the rate of diffusion of a given element to or away from the particle may be mitigated somewhat by its tendency to diffuse down the concentration gradient of a different alloying element.

Because of the complexity of the diffusion problem for multi-component superalloys such as LSHR, the present analysis focused on the determination of an effective diffusivity for the alloying element whose behavior appeared to be rate limiting and to which the simple (pseudo-binary) diffusion analysis implied in Eq. [5] could be applied. For LSHR, the work of Campbell et al. ${ }^{[40]}$ suggested that $\mathrm{Cr}$ was rate limiting. Therefore, the diffusivity as a function of temperature was taken equal to the product of the diffusivity of $\mathrm{Cr}$ in nickel $^{[64]}$ (which yielded principally the activation energy/temperature dependence) and a fitting factor, A, to account for the interaction of the various solutes in LSHR, i.e.,

$$
\begin{aligned}
\mathrm{D}_{\text {eff }}\left(\mathrm{m}^{2} / \mathrm{s}\right) & =\mathrm{A} \times \mathrm{D}_{\mathrm{B}} \\
& =\mathrm{A} \times 0.00036 \exp (-34,278 / \mathrm{T}(\mathrm{K})) .
\end{aligned}
$$

The magnitude of A in Eq. [16] was estimated from the static-coarsening data of Gabb et al. ${ }^{[46]}$ In this prior work, samples of various gamma/gamma prime superalloys were isothermally heat treated at various temperatures for times ranging from 0 to 1000 hours. For example, for the heat treatment of LSHR at $1363 \mathrm{~K}$ $\left(1093^{\circ} \mathrm{C}\right)$, the $2 \mathrm{D}$ coarsening rate constant was determined to be $9.81 \times 10^{-8} \mu \mathrm{m}^{3} / \mathrm{s}$. Using a stereological correction factor of 1.225 or 1.167 (i.e., 5 pct. less per the discussion at the end of Section II-B-1), the corresponding $3 \mathrm{D}$ coarsening rate constant was thus between 1.56 and $1.80 \times 10^{-7} \mu \mathrm{m}^{3} / \mathrm{s}$.

Theoretical predictions of the coarsening rate constant for LSHR at $1366 \mathrm{~K}\left(1093{ }^{\circ} \mathrm{C}\right)$ were obtained by applying Eq. [11] for each of the substitutional solutes in LSHR (Table II). Initial calculations assumed the diffusivity given by Eq. [16] with $\mathrm{A}=0.25$ and the specific thermodynamic factor pertaining to $\mathrm{Cr}$ as being applicable for all of the solutes. Using the values for the various concentration terms given in the table, it was found that the predicted coarsening rate constant for $\mathrm{Cr}$ (column 4) was quite similar to the measurement; the predicted coarsening rate constants for the other solutes were a factor of two or more greater. As shown in column 7 of Table II, a similar conclusion was drawn when the diffusivities of the various solutes were taken to be in the ratios (relative to that of $\mathrm{Cr}$ ) suggested by the work of Campbell et al., ${ }^{[40]}$ and the pertinent thermodynamic factors for each element were used in the calculations. To a first order, therefore, it can be surmised that the diffusion of $\mathrm{Cr}$ (with $\mathrm{A}=0.25$ in Eq. [16]) is rate limiting with regard to processes such as coarsening (and growth) of precipitates.

Kuehmann and Voorhees ${ }^{[24]}$ demonstrated that rapidly-diffusing solutes can also affect the coarsening rate and related diffusional processes for ternary alloys. For multi-component alloys, their work suggests that an effective rate constant $\left(\mathrm{K}_{\mathrm{eff}}\right)$ equal to the inverse of the sum of the inverse rate constants for the individual solutes can be defined, i.e.,

$$
\frac{1}{\mathrm{~K}_{\mathrm{eff}}}=\frac{1}{\mathrm{~K}_{1}}+\frac{1}{\mathrm{~K}_{2}}+\frac{1}{\mathrm{~K}_{3}}+\cdots
$$

Such an approach would result in a value of $\mathrm{A}$ in Eq. [16] of 0.4, rather than 0.25. Thus, most of the

\begin{tabular}{|c|c|c|c|c|c|c|}
\hline Element & $\mathrm{C}_{\gamma}$ & $\mathrm{C}_{\gamma^{\prime}}$ & $10^{7} \times \mathrm{K}^{* *}$ & $\mathrm{D} / \mathrm{D}_{\mathrm{Cr}}$ & $\mathrm{TF}$ & $10^{7} \times \mathrm{K}$ \\
\hline $\mathrm{Cr}$ & 0.1651 & 0.0211 & 1.51 & 1.00 & 1.26 & 1.51 \\
\hline $\mathrm{Al}$ & 0.0655 & 0.120 & 4.82 & 3.07 & 2.5 & 7.71 \\
\hline $\mathrm{Ti}$ & 0.0329 & 0.0786 & 3.56 & 2.33 & 1.97 & 5.54 \\
\hline $\mathrm{Co}$ & 0.2226 & 0.112 & 3.32 & 4.90 & 0.93 & 19.5 \\
\hline Mo & 0.0186 & 0.0075 & 34.9 & 1.88 & 0.96 & 8.75 \\
\hline $\mathrm{Nb}$ & 0.0077 & 0.0161 & 24.9 & 2.14 & 1.25 & 5.82 \\
\hline $\mathrm{Ta}$ & 0.0038 & 0.0096 & 25.7 & - & 1.2 & - \\
\hline $\mathrm{W}$ & 0.0138 & 0.0124 & 1703 & 1.57 & 1.14 & 2678 \\
\hline
\end{tabular}
calculations in Section IV-C made use of A $=0.25$ or

Table II. Calculations for Coarsening Rate Constant $\mathrm{K}\left(\mathrm{mm}^{3} / \mathrm{s}\right)$ at $\mathrm{T}=1366 \mathrm{~K}\left(1093{ }^{\circ} \mathrm{C}\right)^{*}$ 
0.40 , with selected calculations done with $\mathrm{A}=0.5$ and 1.0 to test the sensitivity of model predictions to the specific choice of $\mathrm{D}_{\text {eff }}$.

\section{Simulation Approach}

The model formulation and input data summarized in Sections IV-A and IV-B, respectively, were incorporated into a "fast-acting" Excel-spreadsheet analysis of intragranular, secondary gamma-prime precipitation during continuous cooling. The numerical approach was analogous to that originally proposed by Kampmann and Wagner $^{[31]}$ in that steps of nucleation followed by growth were used to populate a series of bins of precipitates of different sizes. The number of bins required was relatively small (typically 4 to 8 ) due to the fact that the high-temperature nucleation events took place over a very narrow temperature/time interval during which the supersaturation dropped enough to preclude formation of additional precipitates; diffusional growth of the precipitates predominated at longer times.

For most of the simulations, the time increments used for the nucleation event were in the range of 0.4 to 0.8 or 1.5 to 3 seconds for the faster and slower cooling rates, i.e., $139 \mathrm{~K} / \mathrm{min}$ and $11 \mathrm{~K} / \mathrm{min}\left(139{ }^{\circ} \mathrm{C} / \mathrm{min}\right.$ and $11^{\circ} \mathrm{C} /$ $\mathrm{min})$, respectively. Simulations with shorter or longer nucleation time intervals (giving rise to different numbers of bins) showed essentially no difference in predicted results. The diffusion process between nucleation events was discretized into 0.01 or 0.02 second intervals (for the faster and slower cooling rates) to capture the initially-rapid growth of the nanometer-scale critical nuclei at high temperatures. Following the completion of nucleation, the time increment for the diffusion simulations was gradually increased with falling temperature to a maximum of 0.05 second for the faster cooling rate and 1 second for the slower rate.

Several features were included in the simulations to simplify the solution procedure. First, the material coefficients for LSHR were such that the incubation time $\tau$ (Eq. [4]) was quite small, e.g., 0.018 seconds at $1403 \mathrm{~K}\left(1130{ }^{\circ} \mathrm{C}\right)$, relative to the time interval over which nucleation occurred. Thus, nucleation was assumed to proceed at the calculated steady-state rate $\left(J_{\mathrm{o}}\right)$ for all times. Second, the relation between $\Omega$ and $2 \lambda^{2}$ was fit to a sixth-order polynomial to avoid the solution of Eq. [6] for each step in the diffusional-growth calculation.

The increase in average size of the secondary gammaprime precipitates due to coarsening was estimated to be small for the times involved in the cooling process, and was neglected.

\section{Simulation Results and Comparison to Measurements}

Spreadsheet simulations of the precipitation of secondary gamma prime in LSHR were performed for the purpose of model validation (via comparison with the experimental measurements) and model-input-parameter sensitivity analysis. From a broad perspective, the simulation results provided insight into the competition between nucleation and growth which gives rise to a large number fraction of fine particles for faster cooling rates and a smaller number fraction of coarse particles for slower cooling rates.

The comparison of simulation predictions (based on $\mathrm{D}=0.25 \mathrm{D}_{\mathrm{B}}$ and $\left.\mathrm{D}=0.4 \mathrm{D}_{\mathrm{B}}\right)$ to experimental data for the cooling rate of $139 \mathrm{~K} / \mathrm{min}\left(139{ }^{\circ} \mathrm{C} / \mathrm{min}\right)$ showed very good agreement (Figure 8 ). For example, the predicted volume fraction dependence on temperature, which varied less than 1 pet for the two values of $D$, was within several volume percent of the measurements (Figure 8a). The difference is likely due to the tendency for measurements using SEM micrographs to be slightly on the high side due to the finite depth of penetration of the electron beam, thus leading to an oversampling of the precipitate phase.

Measurements of the 3D average precipitate size and number per unit volume for the fast cooling rate were well bounded by the simulation predictions for the two values of D (Figures 8(b), (c)). In particular, the good

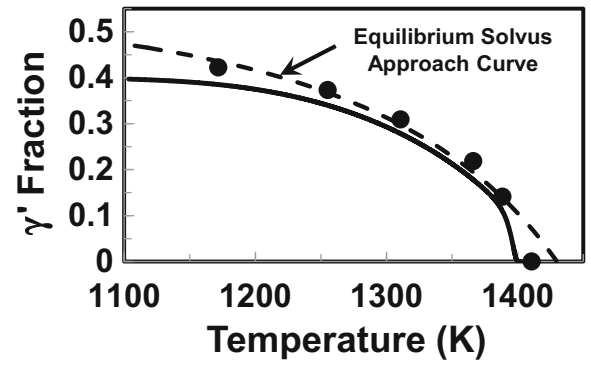

(a)

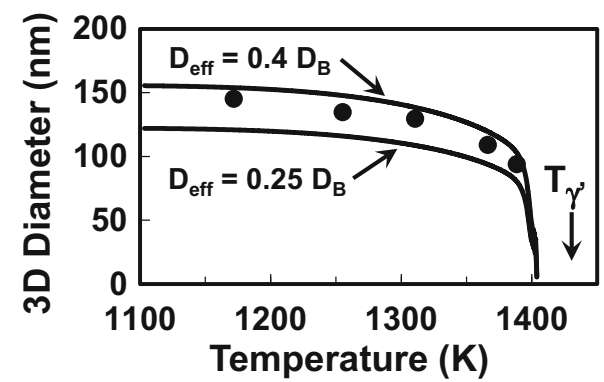

(b)

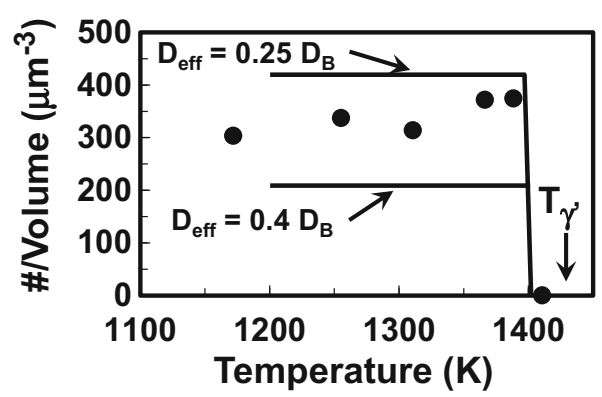

(c)

Fig. 8-Comparison of measurements (data points) and predictions (solid lines) for the evolution of secondary gamma-prime precipitates in LSHR during cooling at a rate of $139 \mathrm{~K} / \mathrm{min}\left(139^{\circ} \mathrm{C} / \mathrm{min}\right):(a)$ Volume fraction, $(b)$ average $3 \mathrm{D}$ diameter, and $(c)$ number per unit volume. In (a), the analytical fit for the equilibrium solvus approach curve is also shown as a broken line. 


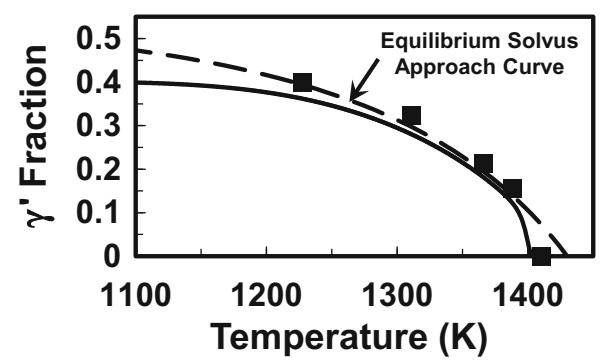

(a)

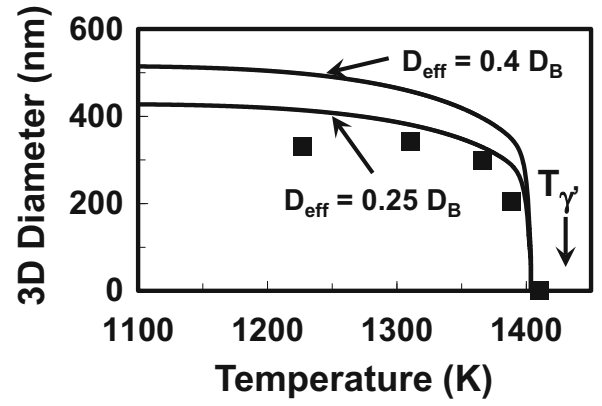

(b)

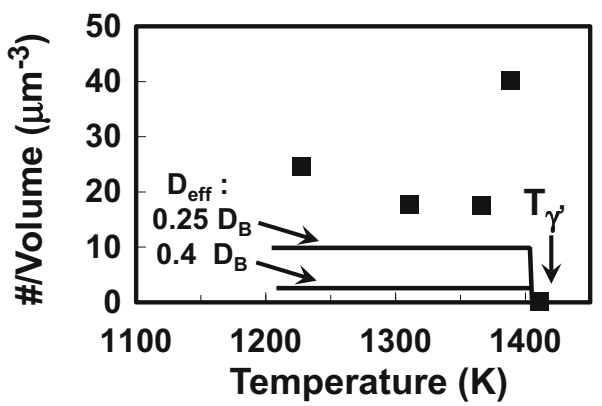

(c)

Fig. 9-Comparison of measurements (data points) and simulation predictions (solid lines) for the evolution of secondary gamma-prime precipitates in LSHR during cooling at a rate of $11 \mathrm{~K} / \mathrm{min}\left(11^{\circ} \mathrm{C}\right.$ / min): (a) Volume fraction, (b) average 3D diameter, and $(c)$ number per unit volume. In (a), the analytical fit for the equilibrium solvus approach curve is also shown as a broken line.

agreement for the number density provided a particularly good validation of the way the model (and accompanying numerical simulations) treat the coupled nucleation and growth phenomena.

A comparison of simulation predictions and measurements for the slower cooling rate (i.e., $11 \mathrm{~K} / \mathrm{min}$, or $11^{\circ} \mathrm{C} / \mathrm{min}$ ) showed approximate agreement, but some significant deviations (Figure 9). As for the faster cooling rate, the volume-fraction dependence on temperature was reasonably well-replicated (Figure 9(a)). By contrast, predictions of the average 3D size showed approximate agreement at high temperatures, but an increasing divergence at lower temperatures (Figure 9(b)). Part of the difference may lie with the inability of $2 \mathrm{D}$ measurements to capture the irregular, 3D shape of the precipitates which had undergone morphological instability at relatively small further undercooling following nucleation and initial growth (Figure 3(b)). ${ }^{[51]}$ For example, depending on the sectioning plane and the actual shape

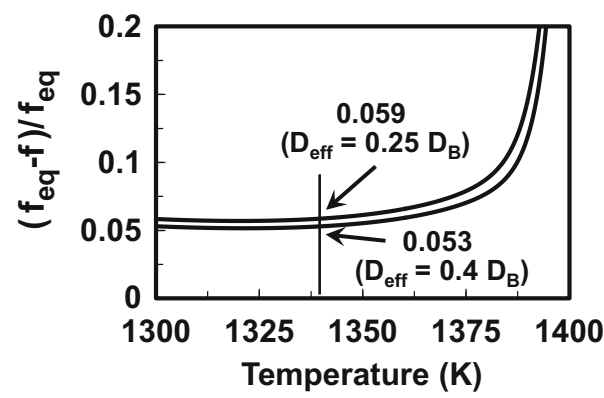

(a)

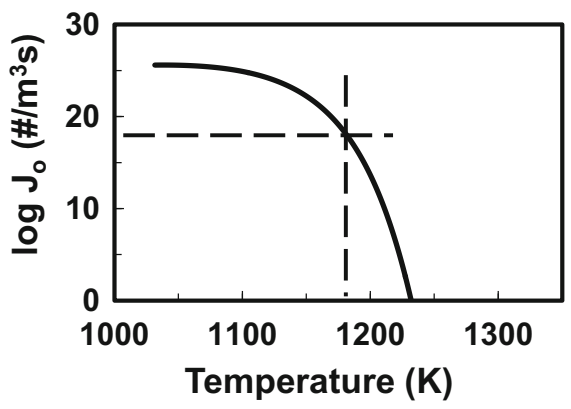

(b)

Fig. 10 - Simulation predictions for gamma-prime precipitation in LSHR during cooling at a rate of $11 \mathrm{~K} / \mathrm{min}\left(11^{\circ} \mathrm{C} / \mathrm{min}\right)$ : $(a)$ the value of $\left(f_{\text {eq }}-f\right) / f_{\text {eq }}$ at high temperatures and $(b)$ the steady-state nucleation rate at lower temperatures.

of the precipitate, a 2D image could reveal several discrete particles which are actually from the same entity in 3D. Such an effect would tend to produce measured average sizes which are on the low side. With regard to the predictions, the diffusion analysis assumed monosized spherical particles whose growth would tend to be higher than that associated with cuboidal or irregularlyshaped lenticular precipitates. ${ }^{[65]}$

Although within a factor of approximately three, the predicted low number density of precipitates in comparison to the measurements for the slower cooling rate (Figure 9(c)) mirrors the differences and has the same sources as those associated with the average size. That is to say, the over-prediction of size is related to the underprediction of number per unit volume for a given overall volume fraction.

Additional simulations of the experimental heat treatments indicated that different time steps during the nucleation interval and hence different numbers of bins (between 4 and 8 ) had little effect on the predictions.

Several other comparisons with experimental observations were used to validate the simulation approach. First, model predictions at $1340 \mathrm{~K}\left(1067{ }^{\circ} \mathrm{C}\right)$ of the difference between the instantaneous volume fraction of gamma-prime precipitate developed during cooling at $11 \mathrm{~K} / \mathrm{min}\left(11^{\circ} \mathrm{C} / \mathrm{min}\right)$ and the equilibrium amount (Figure 10(a)) (i.e., $~ 5.5$ pct.) showed excellent agreement with that deduced from synchrotron data (Figure 5(b)). Second, simulations for the slower cooling rate indicated that the diffusional growth of the secondary gamma-prime precipitates was fast enough to retard the development of a high-enough supersaturation to 
nucleate additional (tertiary) precipitates until a temperature of approximately $1180 \mathrm{~K} \quad\left(907^{\circ} \mathrm{C}\right)$ (Figure 10(b)). This finding is in broad agreement with observations such as those shown in Figures 3(d), (e), (f), and is discussed in greater detail in a forthcoming paper on low-temperature precipitation behavior.

The large difference in average precipitate size and number density for the two cooling rates can be rationalized on the basis of the competition between nucleation and growth. In particular, the reduced diffusional growth of newly-nucleated precipitates for the faster cooling rate enables the development of higher supersaturations and hence higher nucleation rates with decreasing temperature. For the present set of experiments, simulation predictions indicate that the peak nucleation rate for the faster cooling rate was approximately two orders of magnitude higher than that for the slower cooling rate (Figure 11). Even though the time interval over which high-rate nucleation occurs for the faster cooling rate is only one-third that for the slower cooling rate, the high $\mathrm{J}_{\mathrm{O}}$ for the former cooling rate more

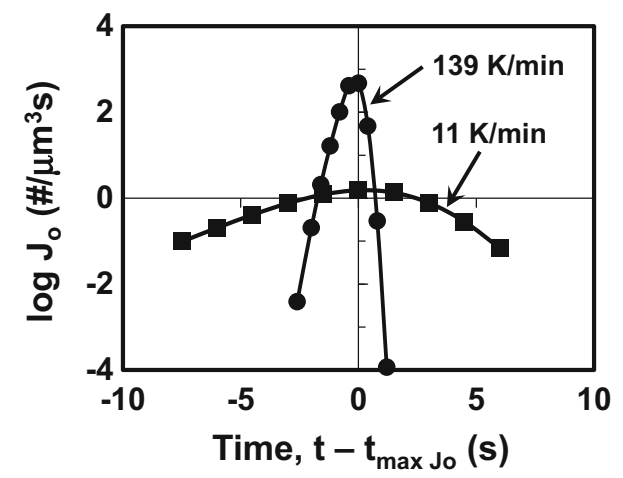

Fig. 11-Simulation predictions of the steady-state nucleation rate $\mathrm{J}_{\mathrm{o}}$ as a function of time for LSHR samples which were supersolvus solution treated and then cooled at two different rates. The abscissa is plotted relative to the time at which $\mathrm{J}_{\mathrm{O}}$ was predicted to be a maximum. than compensates and thus leads to a $\sim 20$-fold increase in overall precipitate number density.

In concert with the narrow temperature and time interval over which nucleation occurs, the simulations yielded predictions of relatively-narrow particle size distributions for the secondary gamma-prime precipitates. For example, for $\mathrm{D}=0.25 \mathrm{D}_{\mathrm{B}}$ and $\mathrm{T}=1250 \mathrm{~K}$ $\left(977^{\circ} \mathrm{C}\right)$, the range of predicted particle sizes with a volume fraction greater than 0.002 was 108 to $127 \mathrm{~nm}$ for the faster cooling rate and 392 to $426 \mathrm{~nm}$ for the slower cooling rate. Hence, the assumption of a monosize distribution utilized in converting experimental (2D) data to $3 \mathrm{D}$ was reasonable to a first approximation.

\section{E. Sensitivity Analysis}

Sensitivity analysis illustrated the relative importance of various material coefficients on simulation results. As examples, predictions of the volumetric number density and average 3D diameter of secondary gamma-prime precipitates formed upon reaching a temperature of $1389 \mathrm{~K}\left(1116^{\circ} \mathrm{C}\right)$, which is below the temperature interval during which nucleation occurs, are summarized in Table III. First, the choice of the value of "C', the matrix solute concentration in Eq. [2], which may be problematical for multi-component systems, was investigated. Irrespective of cooling rate, the simulations revealed that $\mathrm{C}$ equal to $0.25,0.5$, or even the physicallyunrealistic value of 1.0 yielded very similar results. This finding can be rationalized on the basis of the need to nucleate a certain number of particles (which grow at similar rates despite the temporal shift in their formation) to reduce the matrix supersaturation.

Most importantly, the simulation results in Table III demonstrated the major influence of the effective diffusivity $\left(\mathrm{D}_{\text {eff }}\right)$ on simulation predictions. Specifically, a doubling of $\mathrm{D}_{\text {eff }}$ was predicted to decrease the number density by approximately two-thirds and increase the size by $\sim 40$ pct. Hence, factors that influence the diffusivity (e.g., nucleation temperature, concurrent deformation, etc.) will have a substantial effect on the precipitate structure.

Table III. Sensitivity-Analysis for Spreadsheet Simulation of Precipitation in LSHR in Terms of Predictions at $1389 \mathrm{~K}\left(1116^{\circ} \mathrm{C}\right)^{*}$

\begin{tabular}{|c|c|c|c|c|c|c|}
\hline \multirow{2}{*}{$\begin{array}{l}\text { Cooling Rate, } \\
\mathrm{K} / \mathrm{min}\left({ }^{\circ} \mathrm{C} / \mathrm{min}\right)\end{array}$} & \multirow[b]{2}{*}{$\mathrm{D} / \mathrm{D}_{\mathrm{B}}$} & \multirow[b]{2}{*}{$2 \mathrm{C}$} & \multicolumn{2}{|c|}{ With Gibbs-Thompson Correction } & \multicolumn{2}{|c|}{ Without Gibbs-Thompson Correction } \\
\hline & & & \# Ppts $/ \mu \mathrm{m}^{3}$ & Avg Ppt Dia (nm) & $\# \mathrm{Ppts} / \mu \mathrm{m}^{3}$ & Avg Ppt Dia (nm) \\
\hline $139(139)$ & 0.25 & 1.0 & 420 & 80 & 264 & 91 \\
\hline $139(139)$ & 0.25 & 0.5 & 402 & 81 & 259 & 91 \\
\hline 139 (139) & 0.25 & 2.0 & 436 & 80 & 274 & 90 \\
\hline 139 (139) & 0.5 & 1.0 & 143 & 116 & 93 & 132 \\
\hline 139 (139) & 0.5 & 0.5 & 138 & 117 & 111 & 126 \\
\hline $139(139)$ & 1.0 & 1.0 & 49.9 & 165 & 37 & 179 \\
\hline $11(11)$ & 0.25 & 1.0 & 9.76 & 288 & 8.43 & 301 \\
\hline $11(11)$ & 0.25 & 0.5 & 8.55 & 303 & 8.36 & 303 \\
\hline $11(11)$ & 0.25 & 2.0 & 10.9 & 279 & 9.31 & 292 \\
\hline 11 (11) & 0.5 & 1.0 & 4.50 & 377 & 4.01 & 390 \\
\hline $11(11)$ & 0.5 & 0.5 & 3.89 & 394 & 3.75 & 401 \\
\hline $11(11)$ & 1.0 & 1.0 & 2.67 & 454 & 0.97 & 621 \\
\hline
\end{tabular}

*In all cases, $\sigma=23 \mathrm{~mJ} / \mathrm{m}^{2} ; \mathrm{D}_{\mathrm{B}}=$ diffusivity of chromium in nickel. 
The effect of the Gibbs-Thompson (G-T) correction for the matrix composition adjacent to the precipitate on precipitation behavior was also quantified by the sensitivity analysis (Table III). Not surprisingly, neglect of the G-T effect resulted in predictions of larger particle sizes and reduced number densities. Such trends can be rationalized on the basis of predicted more rapid initial growth of the nanometer scale nuclei which depletes matrix supersaturation more quickly than when the G-T correction is included.

\section{SUMMARY AND CONCLUSIONS}

A series of laboratory (interrupted-cooling) and in situ (synchrotron) experiments was performed to provide insight into the kinetics of nucleation and growth of the high-temperature (secondary gamma-prime) precipitates in a typical PM superalloy, LSHR, during cooling at 139 or $11 \mathrm{~K} / \mathrm{min}\left(139\right.$ or $\left.11^{\circ} \mathrm{C} / \mathrm{min}\right)$ following supersolvus solution treatment. From this work, the following conclusions were drawn:

1. Nucleation occurs at a relatively small undercooling $\left(\sim 30 \mathrm{~K}\right.$, or $\left.30^{\circ} \mathrm{C}\right)$ which shows negligible dependence on cooling rate for the parameters investigated. However, the number density of precipitate particles which are formed is a strong function of cooling rate due to its effect on diffusional growth which serves to deplete the matrix supersaturation necessary to drive nucleation. Hence, faster cooling rates generate a large number of fine precipitates, and slower cooling rates generate a smaller number of coarser precipitates.

2. Following nucleation, secondary gamma-prime particles grow in an approximately spheroidal fashion for faster cooling rates, but exhibit a morphological instability for the larger sizes developed at the slower cooling rate. Such shapes complicate the quantification of precipitate characteristics via $2 \mathrm{D}$ metallography in slow-cooled samples.

3. Input parameters for the simulation of precipitation in gamma/gamma prime superalloys can be readily determined from measurements of the on-cooling specific heat as a function of temperature and the equilibrium solvus temperature $\left(\Delta \mathrm{G}^{*}\right)$, the average composition of the precipitate phase and equilibrium solvus-approach curve $\left(\Delta \mathrm{G}^{*}\right)$, the temperature at the onset of nucleation $(\sigma)$, and static-coarsening measurements (effective diffusivity, $\mathrm{D}_{\text {eff }}$ ). The present results suggest that the Ni-Cr pseudo-binary can be used as a surrogate to quantify the rate-limiting phenomena controlling precipitation in multi-component alloys such as LSHR.

4. A simple, fast-acting spreadsheet analysis can be used to simulate the discrete nucleation and growth events during precipitation of secondary gamma prime and thus provide quantitative estimates of the volume fraction, average size (and approximate size distribution), and number density as a function of cooling rate. The simulations reveal the great importance of $D_{\text {eff }}$ with regard to its direct effect on particle growth and indirect influence on particle nucleation due to the rate at which matrix supersaturation is depleted during growth. The analysis can also be used to determine the conditions under which lower-temperature (tertiary) gamma prime precipitates are likely to form.

\section{ACKNOWLEDGMENTS}

This work was conducted as part of the in-house research of the Metals Branch of the Air Force Research Laboratory's Materials and Manufacturing Directorate. The support and encouragement of the Laboratory management are gratefully acknowledged. The authors thank P.N. Fagin, J.C. Schuren, A.R. Shiveley, and K. Shiveley for their yeoman service in conducting the experiments and E. Stienecker, E.F. Gaussa, and M.E. Kirby in metallography and analysis of experimental data. Technical discussions with T.P. Gabb, C.K. Sudbrack, and W. Cao are also much appreciated. One of the authors (SLK) was supported under the auspices of contract FA8650-10D-5226.

\section{REFERENCES}

1. T.A. Parthasarathy, S.I. Rao, and D.M. Dimiduk: in Superalloys 2004, K.A. Green, T.M. Pollock, H. Harada, T.E. Howson, R.C. Reed, J.J. Schirra, and S. Walston, eds., TMS, Warrendale, PA, 2004, pp. 887-96.

2. R.W. Kozar, A. Suzuki, W.W. Milligan, J.J. Schirra, M.F. Savage, and T.M. Pollock: Metall. Mater. Trans. A, 2009, vol. 40A, pp. 1588-603.

3. D.M. Collins and H.J. Stone: Inter. J. Plasticity, 2014, vol. 54, pp. 96-112.

4. R.D. Doherty: in Physical Metallurgy, R.W. Cahn and P. Haasen, eds., North-Holland, Amsterdam, 1996, ch. 15.

5. J.W. Martin, R.D. Doherty, and B. Cantor: Stability of Microstructure in Metallic Systems, Cambridge University Press, Cambridge, 1997.

6. D. Turnbull: in Solid-State Physics, vol. 3, F. Seitz and D. Turnbull, eds., Academic Press, New York, pp. 226-306.

7. A. Kelly and R.B. Nicholson: Progress Mater. Sci., 1963, vol. 10, pp. 151-391.

8. K.C. Russell: Phase Transformations, ASM, Metals Park, OH, 1970, pp. 219-68.

9. J.W. Christian: The Theory of Transformations in Metals and Alloys, 2nd ed., Pergamon Press, Oxford, 1975.

10. K.C. Russell: Adv. Colloid Interface Sci., 1980, vol. 13, pp. 205-318.

11. P. Haasen, V. Gerold, R. Wagner, and M.F. Ashby: Decomposition of Alloys: The Early Stages, Pergamon Press, Oxford, 1984.

12. H.I. Aaronson and F.K. LeGoues: Metall. Trans. A, 1992, vol. 23A, pp. 1915-45.

13. H.S. Carslaw and J.C. Jaeger: Conduction of Heat in Solids, Oxford University Press, London, 1959.

14. H.B. Aaron, D. Fainstein, and G.R. Kotler: J. Appl. Phys., 1970, vol. 41, pp. 4404-10.

15. I.M. Lifshitz and V.V. Slyozov: J. Phys. Chem. Solids, 1961, vol. 19, pp. 35-51.

16. C. Wagner: Zeit. Elektrochem., 1961, vol. 65, pp. 581-91.

17. A.J. Ardell: Acta Metall., 1972, vol. 20, pp. 61-71.

18. A.D. Brailsford and P. Wynblatt: Acta Metall., 1979, vol. 27, pp. 489-97.

19. P.W. Voorhees and M.E. Glicksman: Acta Metall., 1984, vol. 32, pp. 2001-11. 
20. P.W. Voorhees and M.E. Glicksman: Acta Metall., 1984, vol. 32, pp. 2013-30.

21. H.A. Calderon, P.W. Voorhees, J.L. Murray, and G. Kostorz: Acta Metall. Mater., 1994, vol. 42, pp. 991-1000.

22. A. Umantsev and G.B. Olson: Scripta Metall. Mater., 1993, vol. 29 , pp. 1135-40.

23. J.E. Morral and G.R. Purdy: Scripta Metall. Mater., 1994, vol. 30, pp. $905-08$

24. C.J. Kuehmann and P.W. Voorhees: Metall. Mater. Trans. A, 1996, vol. 27A, pp. 937-43.

25. H. Wendt and P. Haasen: Acta Metall., 1983, vol. 31, pp. 1649-59.

26. S.Q. Xiao and P. Haasen: Acta Metall. Mater., 1991, vol. 39, pp. $651-59$.

27. J.D. Robson, M.J. Jones, and P.B. Prangnell: Acta Mater., 2003, vol. 51, pp. 1453-68.

28. C.K. Sudbrack, K.E. Yoon, R.D. Noebe, and D.N. Seidman: Acta Mater., 2006, vol. 54, pp. 3199-3210.

29. C.K. Sudbrack, R.D. Noebe, and D.N. Seidman: Acta Mater., 2007, vol. 55, pp. 119-30.

30. A.J. Langer and J.S. Schwartz: Phys. Rev. A, 1980, vol. 21, pp. $948-58$.

31. R. Wagner and R. Kampmann: in Materials Science and Technology, P. Haasen, ed., VCH, Weinheim, Germany, 1991, vol. 5, pp. 213-303.

32. L. Rougier, A. Jacot, C.A. Gandin, P.D. Napoli, P.Y. Thery, D. Ponsen, and V. Jaquet: Acta Mater., 2013, vol. 61, pp. 6396-6405.

33. S.T. Wlodek, M. Kelly, and D.A. Alden: in Superalloys 1996, R.D. Kissinger, D.J. Deye, D.L. Anton, A.D. Cetel, M.V. Nathal, T.M. Pollock, and D.A. Woodford, eds., TMS, Warrendale, PA, 1996, pp. $129-36$.

34. D.U. Furrer: DEng. Thesis, University of Ulm, Ulm, Germany, 1999.

35. D.U. Furrer and H.J. Fecht: Scripta Mater., 1999, vol. 40, pp. 1215-20.

36. T.P. Gabb, D.G. Backman, D.Y. Wei, D.P. Mourer, D.U. Furrer, A. Garg, and D.L. Ellis: in Superalloys 2000, T.M. Pollock, R.D. Kissinger, R.R. Bowman, K.A. Green, M. McLean, S. Olson, and J.J. Schirra, eds., TMS, Warrandale, PA, 2000, pp. 405-14.

37. H.J. Jou, P.W. Voorhees, and G.B. Olson: in Superalloys 2004, K.A. Green, T.M. Pollock, H. Harada, T.E. Howson, R.C. Reed, J.J. Schirra, and S. Walston, eds., TMS, Warrendale, PA, 2004, pp. 877-86.

38. G.B. Olson, H.J. Jou, J. Jung, J.T. Sebastian, A. Misra, I. Locci, and D. Hull: in Superalloys 2008, R.C. Reed, K.A. Green, P. Caron, T.P. Gabb, M.G. Fahrmann, E.S. Huron, and S.A. Woodard, eds., TMS, Warrandale, PA, 2008, pp. 923-32.

39. K. Wu, F. Zhang, S. Chen, W. Cao, and Y.A. Chang: in Superalloys 2008, R.C. Reed, K.A. Green, P. Caron, T.P. Gabb, M.G. Fahrmann, E.S. Huron, and S.A. Woodard, eds., TMS, Warrandale, PA, 2008, pp. 933-39.

40. C.E. Campbell, J.C. Zhao, and M.F. Henry: J. Phase Equilib. Diffus., 2004, vol. 25, pp. 6-15.

41. J. Gayda, T.P. Gabb, and P.T. Kantzos: in Superalloys 2004, K.A. Green, T.M. Pollock, H. Harada, T.E. Howson, R.C. Reed, J.J. Schirra, and S. Walston, eds. TMS, Warrendale, PA, 2004, pp. 323-30.

42. J. Lemsky: Report NASA/CR-2005-213574, Ladish Company, Inc., Cudahy, WI, February 2005. http://gltrs.grc.nasa.gov.
43. S.L. Semiatin, K.E. McClary, A.D. Rollett, C.G. Roberts, E.J. Payton, F. Zhang, and T.P. Gabb: Metall. Mater. Trans. A, 2013, vol. $44 \mathrm{~A}$, pp. $2778-98$.

44. S.L. Semiatin, K.E. McClary, A.D. Rollett, C.G. Roberts, E.J. Payton, F. Zhang, and T.P. Gabb: Metall. Mater. Trans. A, 2012, vol. 43A, pp. 1649-61.

45. S.L. Semiatin, J.M. Shank, A.R. Shively, W.M. Saurber, E.F. Gaussa, and A.L. Pilchak: Metall. Mater. Trans. A, 2014, vol. 45A, pp. 6231-51.

46. T.P. Gabb, A. Garg, J. Gayda, D. Johnson, E. Kang, I. Locci, R.A. MacKay, R. Rogers, C.K. Sudbrack, and S.L. Semiatin: Report NASA/TM-2014-12345, National Aeronautics and Space Administration, Glenn Research Center, Cleveland, OH, 2014, in press.

47. E.E. Underwood: Quantitative Stereology, Addison Wesley, Reading, MA, 1970.

48. J.C. Russ and R.T. Dehoff: Practical Stereology, Kluwer Academic/Plenum Publishers, New York, 2000.

49. J.S. Tiley, A.R. Shiveley. P.A. Shade, J.C. Schuren, P.N. Fagin, and S.L. Semiatin: Unpublished research, Air Force Research Laboratory, 2014.

50. W.W. Mullins and R.F. Sekerka: J. Appl. Phys., 1964, vol. 35, pp. $444-51$.

51. J. MacSleyne, M.D. Uchic, J.P. Simmons, and M. DeGraef: Acta Mater., 2009, vol. 57, pp. 6251-67.

52. S.L. Semiatin: Unpublished research, Air Force Research Laboratory, Materials and Manufacturing Directorate, 2013.

53. L. Kampmann and M. Kahlweit: Berichte der Bunsen-Gesellschaft Physikalische Chemie, 1970, vol. 94, pp. 456-62.

54. M. Perez: Scripta Mater., 2005, vol. 52, pp. 709-12.

55. O. Grong and H.R. Shercliff: Prog. Mater. Sci., 2002, vol. 47, pp. $163-282$.

56. T.P. Gabb, J. Gayda, J. Telesman, and P.T. Kantzos: Report NASA/TM-2005-213645, National Aeronautics and Space Administration, Glenn Research Center, Cleveland, OH, 2005. http://gltrs.grc.nasa.gov.

57. E.J. Payton: PhD Dissertation, The Ohio State University, Columbus, OH, 2009.

58. F. Zhang: Unpublished research, CompuTherm LLC, Madison, WI, 2008.

59. W. Cao, S.-L. Chen, F. Zhang, K. Wu, Y. Yang, Y.A. Chang, R. Schmid-Fetzer, and W.A. Oates: CALPHAD, 2009, vol. 33, pp. 328-42.

60. C. Booth-Morrison, J. Weninger, C.K. Sudbrack, Z. Mao, R.D. Noebe, and D.N. Seidman: Acta Mater. 2008, pp. 3422-38.

61. J.W. Nesbitt and R.W. Heckel: Metall. Trans. A, 1987, vol. 18A, pp. 2061-73.

62. M.A. Dayananda: Mater. Sci. Eng. A, 1989, vol. A121, pp. 35159.

63. S.L. Semiatin, J.M. Shank, W.M. Saurber, A.L. Pilchak, D.L. Ballard, F. Zhang, and B. Gleeson: Metall. Mater. Trans. A, 2014, vol. $45 \mathrm{~A}$, pp. $962-79$.

64. M.S.A. Karunaratne, D.C. Cox, P. Carter, and R.C. Reed: in Superalloys 2000, T.M. Pollock, R.D. Kissinger, R.R. Bowman, K.A. Green, M. McLean, S. Olson, and J.J. Schirra, eds., TMS, Warrandale, PA, 2000, pp. 263-72.

65. S.L. Semiatin, T.M. Lehner, J.D. Miller, R.D. Doherty, and D.U. Furrer: Metall. Mater. Trans. A, 2007, vol. 38A, pp. 910-21. 